\title{
رؤية هقترحة لتحقيق الانتقال السلس للأطفال هن رياض الأطفال إلى المدرسة الابتدائية في ضوء الخبرات العالمية
}

\author{
الدكتورة/ حنان أسعد خوج \\ أستاذ مشارك ـ كلية الآداب والكلوم الإنسانية \\ قسم علم النفس - جامعة الملك عبد العزيز
}


روية مقترحة لتحقيق الانتقال السلس للأطفال من رياض الأطفال إلى المدرسة الابتدائية في ضوء الخبرات العالمية .

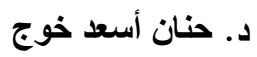


الملخص

هدف البحث إلى التعرف على الخبرات العالمية في تطبيق ممارسات

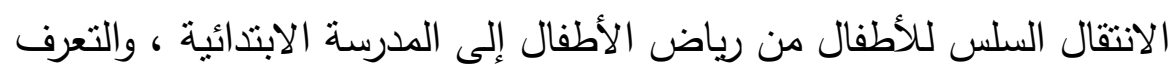
على العوامل المؤثرة في عملية الانتقال ، والتوصل ل لروئية مقترحة لتحقيق الانتقال

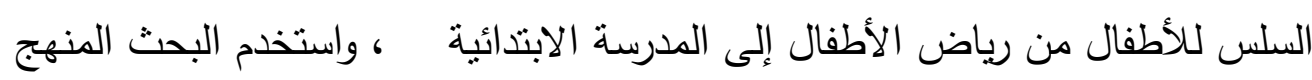
الوصفي التحليلي للوقوف على واقع الانتقال السلس من رياض الأطفال إلى المدرسة

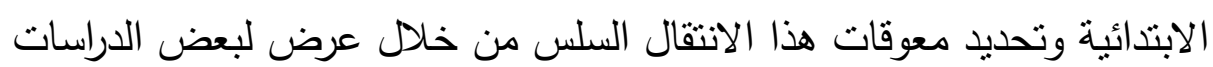

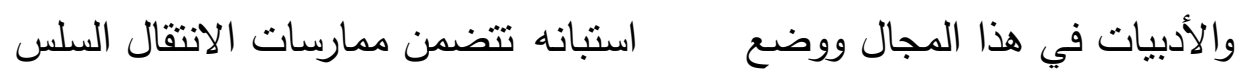
ومعوقاته ومقترحات تحقيقه ،وتوصل البحث إلى عدة نتائج من أهمها:عدم

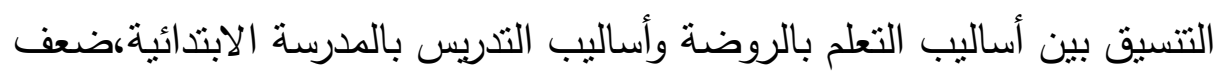

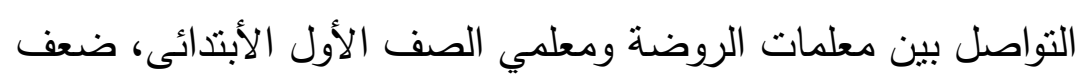
الاستمرارية والتواصل بين ما يقدم في رياض الأطفال من خبرات وما يقدم من مناهج في المدرسة الابتدائية ، عدم وجود أنشطة انتقالية تقوم بها معلمات الروضة

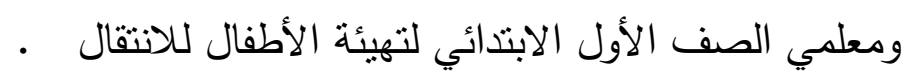

الكلمات المفتاحية : الانتقال السلس ، رياض الأطفال. 
Proposed vision to achieve a smooth transition of children from kindergarten to elementary school in the light of global experiences

\begin{abstract}
:
The research aims to identify the global expertise in applying the practices of a smooth transition of children from kindergarten to elementary school. It also aims to identify the factors affecting the process of transition, and come up with a proposed vision to achieve a smooth transition of children from kindergarten to elementary school. Research used the descriptive analytical approach to find out the reality of a smooth transition from kindergarten to elementary school and to identify the obstacles to the smooth transition through presenting some of the studies and the literature in this area. It uses a questionnaire including the practices of a smooth transition and its obstacles and requirements to be achieved.

The research found several results and the most important of them are: the lack of coordination between learning methods in the kindergarten and teaching methods in primary school, the poor communication between kindergarten teachers and teachers of first grade of the primary stage, the weakness of continuity and communication between the experiences offered in kindergartens and the curricula in the elementary school and the lack of transition activities carried out by kindergarten teachers and first grade teachers to prepare children for this transition.
\end{abstract}

\title{
Key words:
}

smooth transition, kindergarten 


\section{مقدمة}

التعليم هو قاطرة التقدم وأساس البناء وآلية الحراك والموجه في صياغة

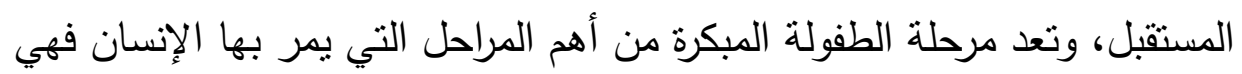

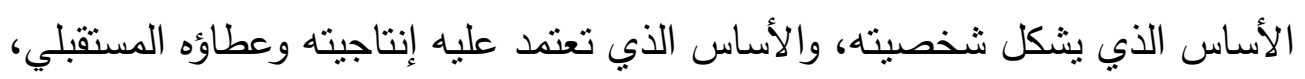
لذا الاهتمام بهذه المرحلة من أهم الأمور الأساسية للطفل، فأطفال اليوم الذين نسلحهم

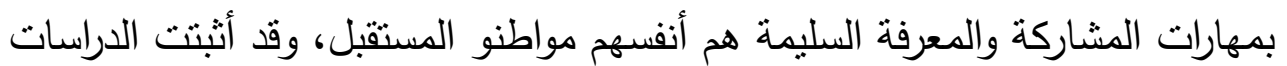
الحديثة أن الخبرات المبكرة لاى الطفل لها تأثثر قوى على طبيعة النمو لديه.

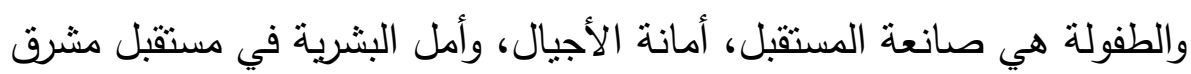

باسم وإذا كنا اليوم في القرن الحادي والعشرين فإن من واجبنا أن نعد أبنائنا لمواجهة المتغيرات التي بدأت معالمها تتفتح في ظل المتغيرات المتسارعة التي تشهدها أيامنا هذه .( بطرس ، 2014 ) ) إن الاهتمام بنربية الأطفال في العصر الحديث ينظر إليه باعتباره مؤشرًا من

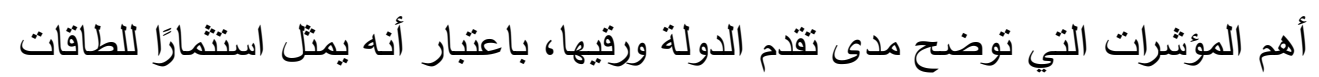
البشرية. والأطفال هم النواة الأولى لهذه الطاقات والتي من خلالها تخطو الأمم خطواتها الأولى نحو تحقيق سبل التقدم والرقى، فهي المرحلة التي تتفتح فيها مدارك الطفل على خبرات جديدة من خلال ما تقدمه الروضة من برامج وأنشطة تهدف إلى تتمية الأطفال من مختلف النواحي الجسمية والاجتماعية والعقلية، و تهيئتهم للحياة المدرسية النظامية في مرحلة التعليم الأساسي، عن طريق الانتقال التدريجي من مناخ الأسرة إلى مناخ المدرسة.

ومن ثم تمثل مرحلة الطفولة نقطة البداية في المسار التعليمي، حيث يتلقى فيها الأطفال تعليماً يساعدهم في الاستعداد لدخول المدرسة، فالأطفال الذين يشاركون في

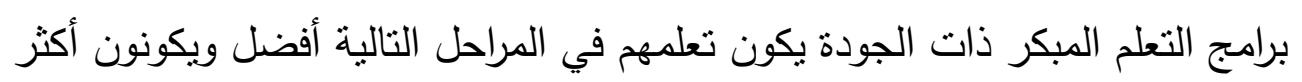
نجاحاً في المدرسة إذا هيئت لهم البيئة المناسبة. 
كما أوضحت العديد من الدراسات الأهمية البالغة لمرحلة ما قبل المدرسة،

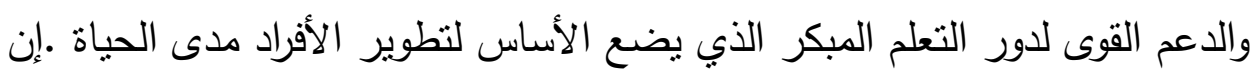

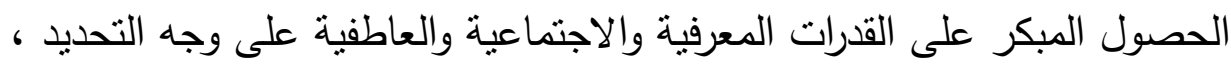
جعل أنشطة التعلم لاحقًا أكثر فعالية ـ إن البلدان في جميع أنحاء العالم أدركت واته تدريجيًا أهمية مرحلة ما قبل المدرسة، وهكذا الرعاية والتعليم في مرحلة الطفولة المبكرة

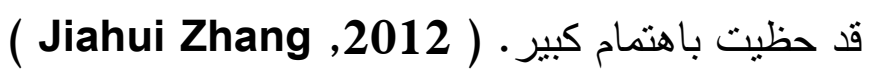
إن انتقال الطفل من مرحلة الطفولة المبكرة إلى مرحلة الالتحاق بالمدرسة يعد التحا

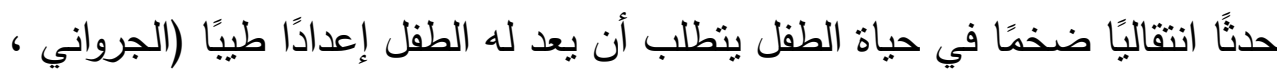

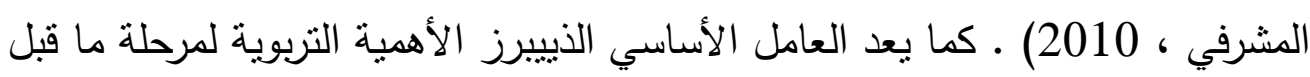

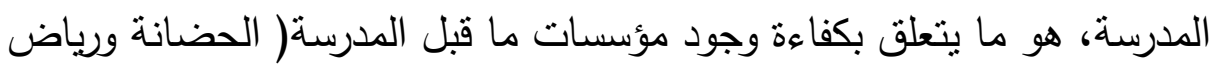
الأطفال )القادرة على تحقيق النمو الشامل للطفل خلال هذه المرحلة المبكرة من العمر ، وذللك بتوفير المناخ السليم لنمو الطفل عقليًا ونفسيًا، واجتماعيًا وجسمانيًا، وبناء شخصيته المتكاملة .( الناشف ، 2006) وتعد المرحلة الابتدائية من أكثر مراحل التعليم أهمية باعتبارها بداية التعليم

الإجباري، إذ إنها الفترة التي تتشكل فيها شخصية الفرد ، ففي هذه المرحلة يكتسب

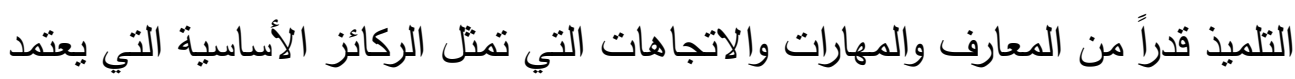
عليها نموه في المراحل التالية. وأولى إعلان دمشق لرعاية وتربية الطفولة المبكرة (2010) عن توصيات

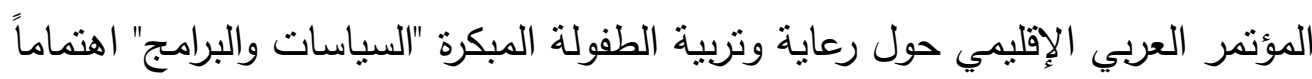
بعمليتي الانتقال والاستعداد ويقصد بها كيفية انتقال الطفل واستعداده من البيت إلى رياض الأطفال ثم الانتقال من رياض الأطفال إلى المدرسة النظامية- وكان هذا في السابق يتم دون اهتمام أو تركيز حول ما يطلب من ارشادات وتوجيهات للأسرة والمعلم

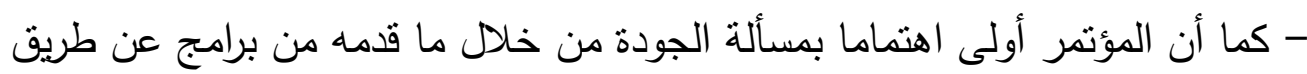
إيجاد إطار عمل إقليمي في قضايا أساسية وهي التنسيق والتكامل بين القطاعات 
العاملة في مرحلة الطفولة المبكرة والجودة والفعالية والاستعداد والانتقال من البيت إلى

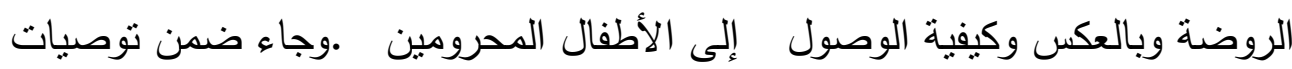

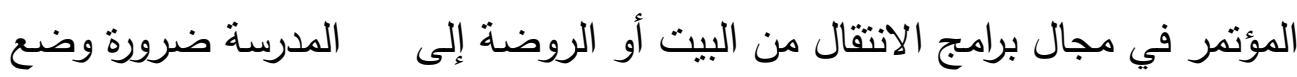

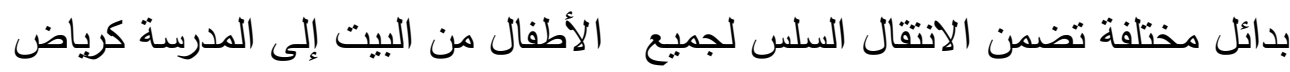
الأطفال ومراكز مجتمعية وبرامج موجهة للأسرة وبرامج صيفية و تهيئة المدرسة لتأمين

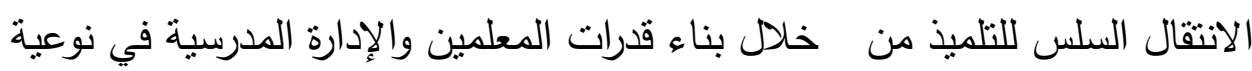
التقاعل والاستجابة للطفل بشكل يساعده على الاستمرار في المدرسة. ويتأثر انتقال الطفل من الروضة إلى المدرسة الابتدائية بعدة عوامل منها:

\section{1. القلق والخوف عند الأطفال:}

حيث يقابل انتقال الأطفال من الروضة إلى الصف الأول الابتدائي بمشاعر البهجة والقلق معًا فالبهجة تكون في متعة الطفل في إنجاز أنثياء جديدة يتحدى فيها

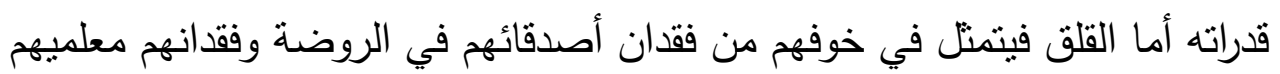
وبسبب الخوف من المجهول الذي يواجههم بعد التحاقهم بالمدرسة.

(Brostrom, 2003)،(Einarsdottir,2003a)

والقلق عند الأطفال يتمثل من حجم العمل المطلوب أداؤه وكذلك افتقاد الطفل للكثير من الأنشطة التي يتمتع بها في الروضة، وقلة فرص الاختيار لايه، ومطالبته

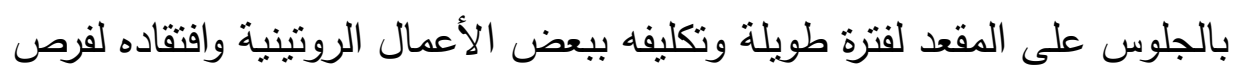

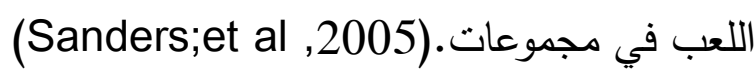
كما جاء في دراسة فابيان ( Fabian, 1998 ( أن الأطفال يشعرون بالقلق والعصبية والتحمس عندما يقترب موعد الانتقال من الروضة إلى المدرسة الابتدائية بألمانيا، كما أكد البحث الذي قام به جربيل ونيسل (Grieble, NiesesI , 2002) على أن معظم الأطفال يصيبهم القلق عند دخولهم المدرسة. 
وأكدت نتائج دراسة مارجينس Margetts,2000a)على أن الأطفال الذين

كانت لديهم مشكلات سلوكية كالعدوان وفرط النشاط كانوا أكثر صعوبة في التكيف مع دري السنة الأولى من المدرسة الابتدائية في ألمانيا. ويرى فابيان (Fabian,2000a) أن الناحية الاجتماعية والانفعالية للأطفال تعتبر من الأمور الرئيسة في تكيفهم مع المدرسة في ألمانيا فالثبات الانفعالي والاتجاهات الإيجابية التي يكونها الطفل عن المدرسة وعن عملية التعلم بها، والقدرة على الاتصال الفعال من العوامل الضرورية لاستمرار عملية التعلم - لأن الأطفال السعداء الآمنين لديهم القدرة على المشاركة بفاعلية والقدرة على التعامل مع التحديات التعليمية التي تواجهرم.

وتوصلت دراسة مسينتز (Mcinture, et al ,2007) إلى أن هناك عوامل تساهم في الانتقال الناجح من الروضة إلى المدرسة الابتدائية وهذه العوامل تقوم بدوراً حيوياً في إعداد الطفل للتحديات التي تواجهه بالتعليم الابتدائي، ومن هذه العوامل: الاستعداد البدني والجسمي، المهارات المعرفية واللغوية، النمو العاطفي والاجتماعي. كما هدفت دراسة (Grieble, Niesesl , 2001 ) إلى إلقاء الضوء على

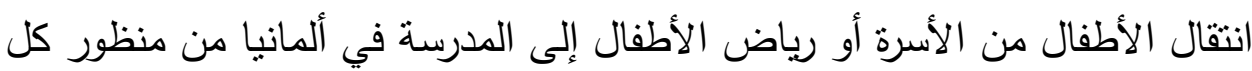

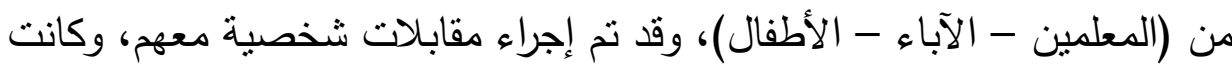
عينة الدراسة عبارة عن مجموعة من المعلمين والأطفال وأولياء أمورهم، وتوصلت التراء الدراسة إلي عدة نتائج من أهمها أن التعرف على خبرات الأطفال حول عملية الانتقال إلى المدرسة يعد ضروريا لإعداد الأطفال للمدرسة. ومن ثم فإن انتقال الطفل من الروضة إلى المدرسة الابتدائية يصاحبه مشاعر من الخوف والقلق نتيجة الانتقال لبيئة جديدة وفقدانه اصدقائه ومعلميه الذين تعود عليهم وكذللك افتقاد البيئة الجديدة للأنشطة التي تعود عليها وكان يستمتع بها في الروضة ، ويحتاج التعامل مع هذه المشاعر درجة عالية من الاتصال الفعال بين 
الروضة والمدرسة وإعداد الطفل للتحديات التي تواجهه عند انتقاله للمدرسة وكذلك ضرورة مراعاة النمو الانفعالي لدى الطفل. r. اختلاف وجهات نظر معلمات الروضة ومعلمي الصف الأول الابتدائي: توجد اختلافات واضحة بين رؤية معلمات الروضة لعملهم ورؤية معلمي المدرسة الابتدائية، حيث ترى معلمات الروضة أن الروضة فترة للعب، وأن عملهن

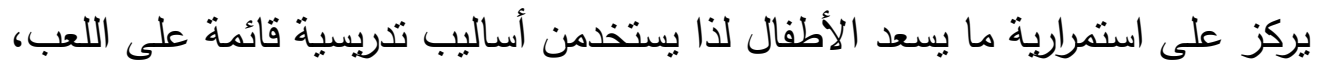

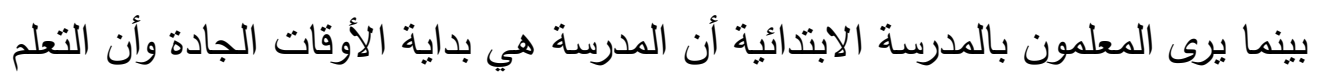

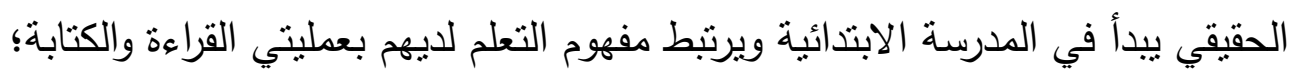
لذا يركز معلمو المدرسة الابتدائية في تدريسهم على المحتوى الذي يركز على المعلم بدلا من المتعلم.. (Einarsdottir,2003b) واختلاف الرؤى بين كل من معلمات الروضة ومعلمي الصف الأول الابتدائي يؤثز في عملية التفاعل والتعاون فيما بينهم ويجعل كلا مهنم يعمل بصورة مختلفة تمامًا عن الآخر الأمر الذي يؤثز على عملية الانتقال، ونجد أن هناك صور من الضعف في التواصل بين كل من الفئتين نظهر فيما يلي: ثلة معرفة كثير من معلمي المرحلة الابتدائية بالبرامج الملائمة لأطفال الروضة لفئ، ويعتقدون أن أطفال الروضة، يتعلمون بالطريقة نفسها التي يتبعونها مع الأطفال الأكبر سنًا، ويستخدمونها في المدرسة الابتدائية. (بدر، 2002) خعف اهتمام معلمي المدرسة الابتدائية بما تفعله معلمات الروضة وما تقدمه

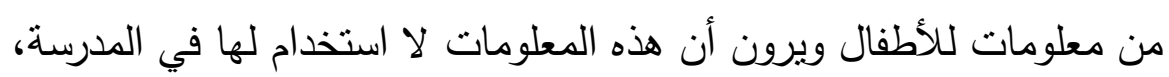

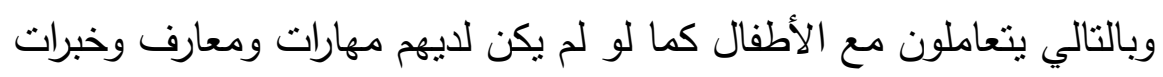

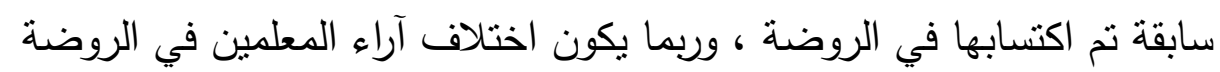

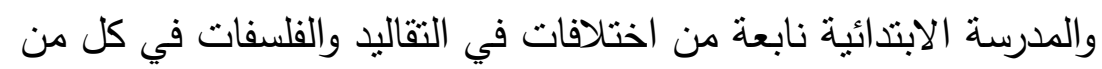

المؤسستين. ( Brostrom,2003) 
حعوبة إقامة المعلمون بالمدرسة الابتدائية لعلاقة ترابطية بين المناهج الدراسية Office for Standards In بالروضة والمناهج في الصف الأول الابتدائي.

(Education, 2003)

كما استهدفت دراسة (Einarsdottir, 2003a)الكثف عن وجهات نظر المعلمين حول المشاكل التي يواجهها الأطفال الجدد الملتحقين بالمدارس الابتدائية، نم تطبيق استبيان على ( 270) من معلمي الصف الأول الابتدائي ومعلمات الروضة

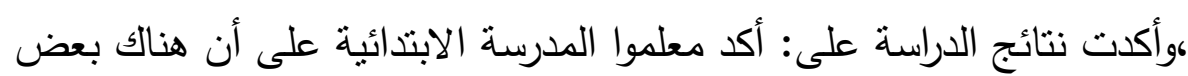

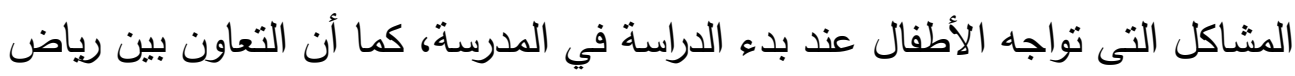

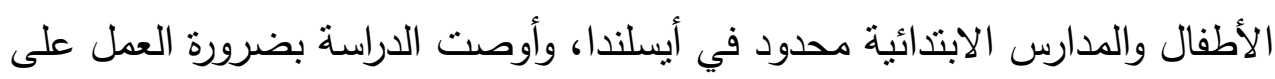
الاستمرارية والتعاون بين المؤسستين، كما ينبغي أن يكون هناك تتسيق بين المناهج وطرق التدريس عند الانتقال من الروضة إلى الصف الأول الابتدائي. ونستخلص مما سبق أن هناك اختلافات في الرؤى ووجهات النظر بين الني معلمات الروضة ومعلمي المدرسة الابتدائية من حيث المحتوى الذي يقدم للطفل

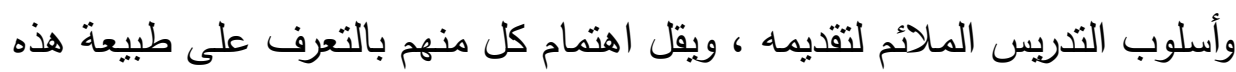
المرحلة والخبرات السابقة لدى الطفل حتى يتم نقله بصورة تدريجية من الروضة إلى الى ولى المدرسة الابتدائية.

r. اختلاف صورة المنهج في كل من الروضة والمدرسة الابتدائية:

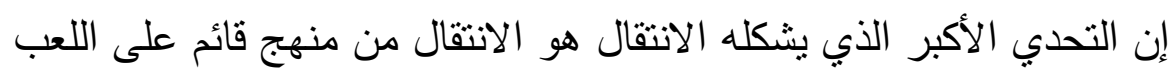
في الروضة إلى مناهج تتظيمية في الصف الأول من التعليم الأساسي، حيث يعتبر تقديم القراءة والكتابة ودروس الرياضيات ساعة يوميًا لتلاميذ الصف الأول الابتدائي تحديًا لأنه من الصعب جعل الأطفال يجلسون ويستمعون إلى المدرس لفترة طويلة. كما يواجه الأطفال الملتحقون بالسنة الأولى من التعليم الابتدائي موقفًا مختلفًا عن خبراتهم في الروضة أو المنزل سواء كان في المنهج أو المكان أو المجتمع بانه 
المدرسي ككل، وهذه الاختلافات ربما تؤثر على تكيفهم مع المدرسة ويصاحبها نتائج سلبية على عملية التعليم. كما أن المدرسة الابتدائية تختلف في سماتها عن رياض الأطفال حيث يستخدم في الروضة المدخل البنائي فيتعلم الأطفال بأنفسه كل شيء، أما في المدرسة الابتدائية فيتم التعلم من خلال تدريسهح كيف يقرأون ويكتبون، وتكليفهم بواجبات منزلية كثيرة مرهقة عكس ما كان عليه الحال بالروضة، وهذا يتطلب مهارات معقدة تكون أصعب على الطفل عما تلقاه في الروضة، و يجعل من المدرسة مكانًا ينفر منه الأطفال بقبولهم التغيرات التي تحدث في المدرسة.(Phatudi,2007)، (بيرد، 2007) وهذا ما أثنار إليه (Margetts,2006)إلى أن التقدم والاستمرارية في عملية

الانتقال قد تتعطل بسبب التغيرات المفاجئة في أساليب التدريس والمناهج في الصف إنف الأول الابتدائي حيث يتسبب الطابع التعليمي القائم على الإلقاء في تعلم القراءة والكتابة

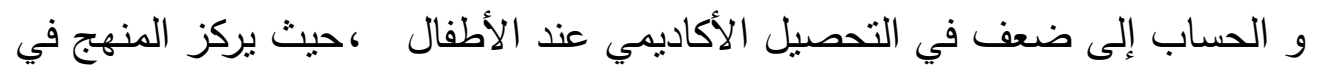

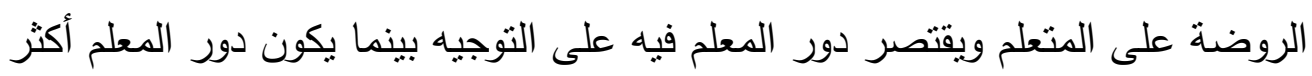
ظهوراً في المدرسة الابتدائية ويقل التركيز على الطفل. وتوصلت دراسة (Margetts, 2002b) إلى: أن الاختلافات بين برامج

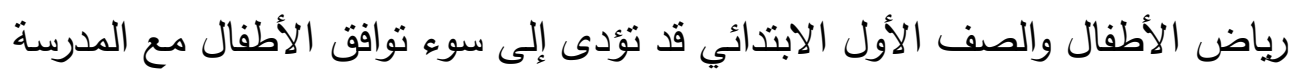

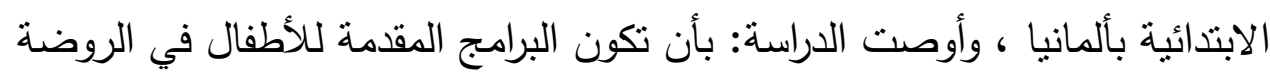
على درجة مناسبة من الاستمرارية. كما استهدفت دراسة (Grieble, Niesesl , 2000) التعرف على توقعات الأطفال عن الحياة المدرسة قبل التحاقهم بها، وكيف أن هذه التوقعات تتأثز بثقافة كل من رياض الأطفال والأسرة معاً، وكان من أهم نتائج هذه الدراسة: أن فلسفة رياض وناض

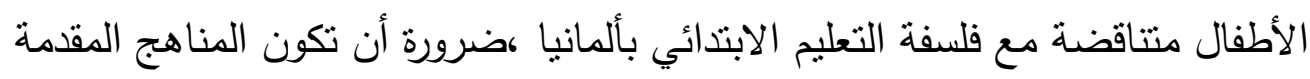
للأطفال بالصف الأول الابتدائي تتصف بقدر من المرونة. 
ومما سبق نلخص إلى أن صورة المنهج في الروضة تختلف عن صورته في

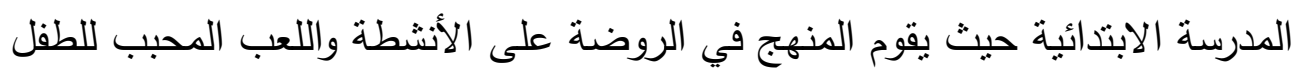

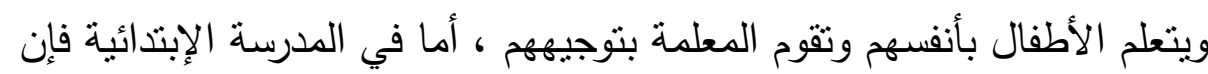
المناهج تركز على تعليم القراءة والكتابة والحساب من خلال التعلم القائم على الإلقاء

ويتم التركيز على دور المعلم ويتم تكليف الطفل بواجبات وتكليفات منزلية كثيرة . ؛. التواصل بين الروضة والمدرسة:

أن درجة التواصل بين الروضة والمدرسة الابتدائية ضعيفة ومن مظاهر ذلك

الضعف :عدم تكيف بعض الأطفال مع المدرسة الإبتدائية نتيجة لما يواجهونه من العمل الجاد والمهام الإلزامية وقلة الأنشطة ، وعدم استمرارية الخبرات وافتقار المناهج الدراسية للجاذبية والتتويق، وجود بيئة مدرسية تتسم بالكثافة المرتفعة والطابع التسلطي وكثرة الأوامر ، وتركيز الامتحانات فيها على قياس الحفظ والاستظهار . استهدفت دراسة (Samuel,2006)قياس تأثير برامج تعليم ما قبل المدرسة في زيادة استعداد الأطفال للمدرسة والانتقال الفعال من الروضة إلى المدرسة الابتدائية في كينيا، و دراسة فعالية تلك البرامج في مواجهة الأطفال لتحديات الانتقال، وأكدت نتائج الدراسة على:أن هناك علاقة بين أنشطة الاستعداد للمدرسة الذي تقوم بها الروضة والإنجاز المدرسي والتحصيل الأكاديمي للطفل عند إلتحاقه بالمدرسة. وأكدت دراسة (Peter,2000) على أن الأطفال عند انتقالهم من بيئة المنزل إلى بيئة التعلم الجديدة بالروضة يتكيفون معها بسهولة وذلك لما يجدونه من متعة في اللعب وتتاول الوجبات مع أصدقائهم، أما عند انتقالهم إلى المدرسة لم يتكيفوا معها بها بشكل سريع وذللك لما يواجهونه من العمل الجاد والمهام الإلزامية وقلة الأنشطة، وعدم الاستمرارية في الخبرات المقدمة إلى الطفل من الروضة إلى المدرسة الابتدائية ينتج عنه تحديات وصعوبات كثثرة مما يؤثر على عملية الانتقال وعلى إقبال الأطفال على المدرسة ورغبتهم في التعلم، وفيما يلي سيتم التطرق لأسباب نفور التلاميذ من المدرسة كما حددها كل من (الثيخ، 2007،26)، (الخليلي، 2005، 298) وهى: 
وَجود مناهج دراسية لا تتاسب المراحل العمرية التي يمر بها التلاميذ أو تراعي

اتجاهاتهم وميولهم ولا تلبي مطالبهم واحتياجاتهم،كما تقتقر إلى الجاذبية

والتشويق بسبب غلبة الجانب النظري عليها وقلة النواحي النطبيقية والعملية.

وجود بيئة مدرسية لا برغب التلاميذ فيها: فالفصول مزدحمة ولا توجد مكتبة

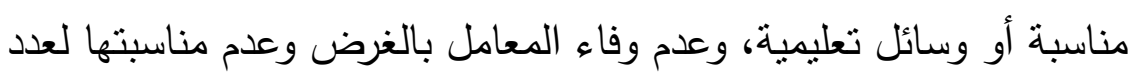

$$
\text { التلاميذ، وعدم وجود ملاعب كافية. }
$$

ثتسام المناخ في بعض الفصول بالطابع التسلطي، والذي يضعف فيه إسهام

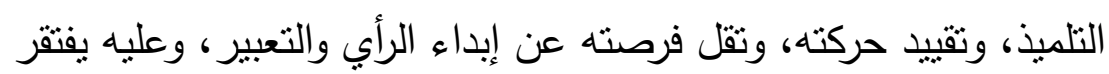

$$
\text { الفصل إلى المناخ الحافز على العمل. }
$$

وَجود العديد من الأمور النفسية التي قد تؤدي إلى عدم رغبة الطفل في المدرسة،

منل الثعور بالرهبة والخوف، والقلق، والخجل، والاضطرابات النفسية؛ منل: نقص الاتزان الانفعالي، وسوء التوافق واضطراب التفكير والتذكر، وعدم إثباع الحاجات النفسية.

ثصور نظام الامتحانات السائدة ؛حيث تركز الامتحانات على قياس قدرة التلاميذ على الحفظ والاستظهار ولا تعتتي بشكل كاف بالوقوف على قدراتهم على الفهم والتحليل والتطبيق، وتقتصر على الجانب المعرفي فقط. •. التواصل بين الأسرة وكل من الروضة و المدرسة الابتدائية: تعتبر مشاركة الوالدين جزءًا أساسيًا من بنية التعليم الجيد؛ لأن الآباء هم الذين والأين

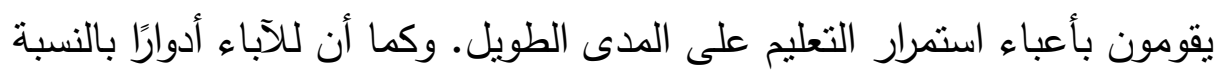
لرعاية أطفالهم، إلا أنهم في حاجة إلى أن يكونوا مدعمين رئيسيين في عملية تعليمهم،

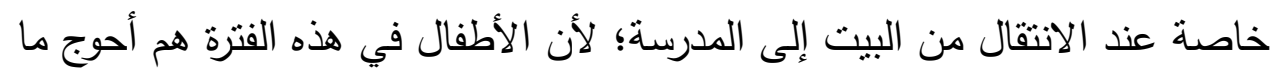

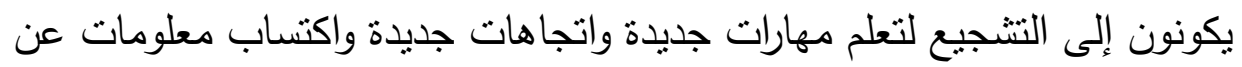
المدرسة وكيف ينتظمون فيها. (بدير، 2007، 176) 
وهدفت دراسة 2007, Mcinture, Laura, et al () إلى تحديد دور الأسرة في

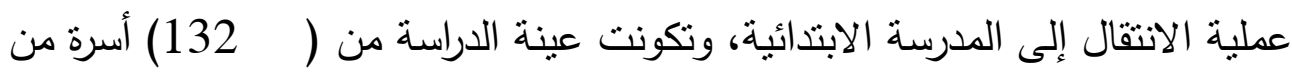

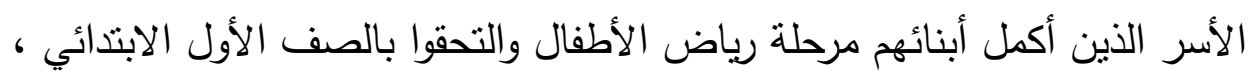

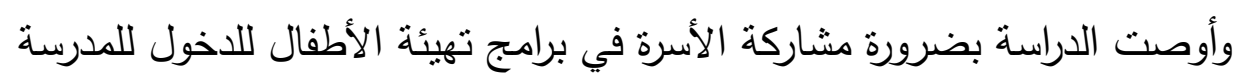

الابتدائية

كما هدفت دراسة (Nelson,2004) إلى توضيح دور الآباء والمعلمين في

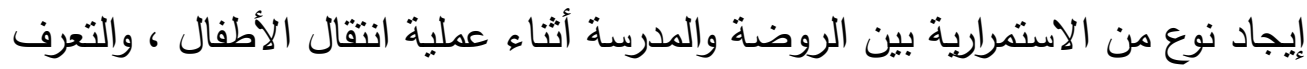
علي مدى تطبيق ممارسات الأنتقال فى الروضات والمدارس، وتكونت العينة من أكثر الترات

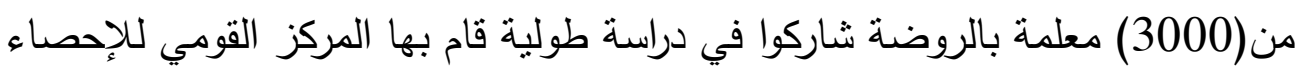
بالولايات المتحدة الأمريكية، وتوصلت الدراسة إلى أن إرسال معلومات للأسر عن التران

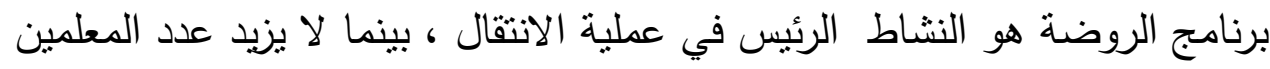
الذين يقومون بالزيارات المنزلية عن 5\%، و من أسباب عدم قيام المعلمين بزيارات قلة

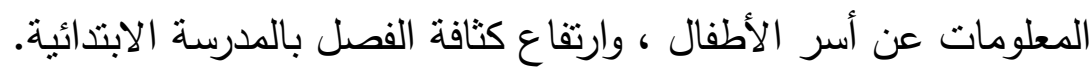
كما هدفت دراسة ( Fabian,2000b) إلي التعرف على آراء الآباء في عملية الآلية الانتقال ومقارنتها بآراء المعلمين والأطفال، تم تطبيق الدراسة على عينة من الأطفال

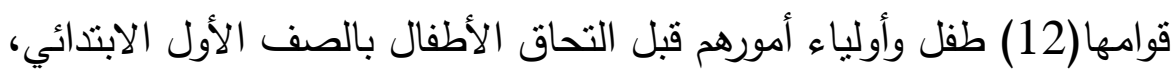

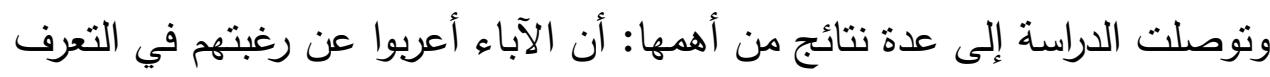

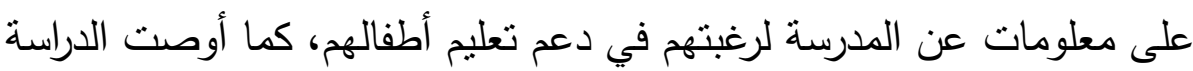

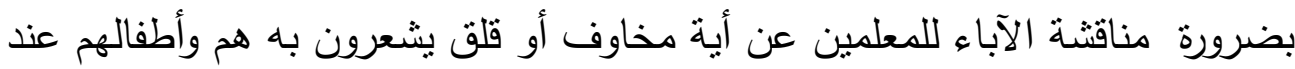

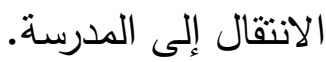

يتضح مما سبق أن النواصل بين الأسرة وكل الروضة والمدرسة الإبندائية يلعب دورا كبيرا في جعل انتقال الطفل من الروضة إلى المدرسة الابتدائية أكثر سهولة الإنية

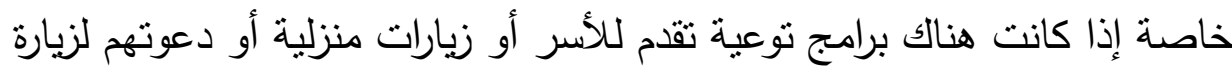
الروضة والمدرسة لمناقثتهم حول صعوبات ومشكلات انتقال أطفالهم. 


\section{ج. الصداقات بين الأطفال وعلاقتها بعملية الانتقال:}

تعد الصداقات نوعًا من أنواع التفاعل الاجتماعي الذي لا غنى عنه بين

البشر، فهي التي تساعد على تكوين جو من الألفة والحب بين الناس وعليها تبنى الاجنى علاقات التعاون وبها تكسر الحواجز بين البشر، وتتمي شخصية الإنسان من جوانبها المختلفة خاصة من الناحية الاجتماعية.

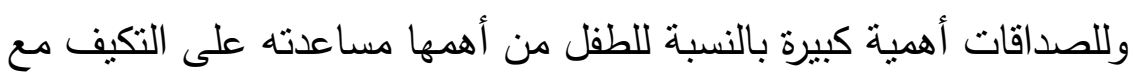

الصف الأول الابتدائي، وهناك العديد من الدراسات التي سلطت الضوء على أهمية

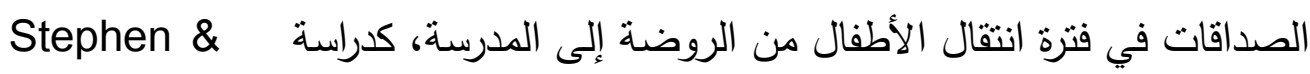

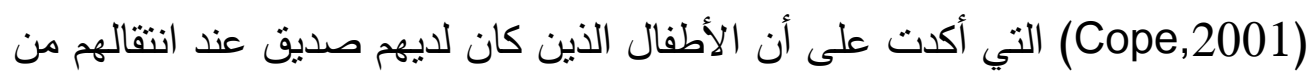
الروضة إلى المدرسة كانوا أكثر تكيفًا مع المدرسة، ويتعاملون بود ولطف مع أقرانهم

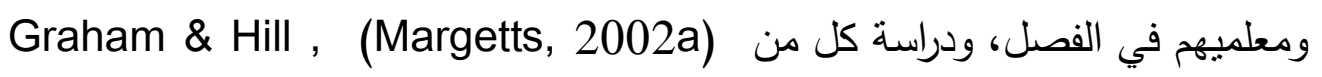
(2003)والتي أكدت على أن تكوين الصداقات قبل التحاق الطفل بالمدرسة يساعد في تكيفه مع أقرانه داخل الفصل؛ حيث يجد وجوه مألوفة في بيئة غير مألوفة . كما هدفت دراسة (Margetts, 2008) إلى التعرف على توقعات الأطفال عن

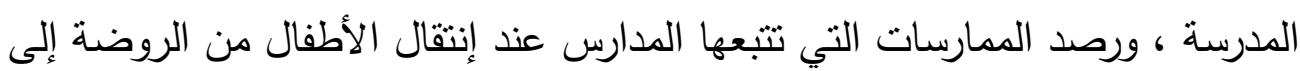
الصف الأول الابتدائي، وكانت عينة الدراسة ( 54) طفلاً من (4) مدارس مختلفة في

ملبورن في استراليا ، وقد استخدمت الباحثة أسلوب إجراء المقابلات للتعرف على ما وهابـ يحتاج الأطفال لمعرفته عند البدء المدرسة، وقد توصلت الدراسة إلى: أن تكوين

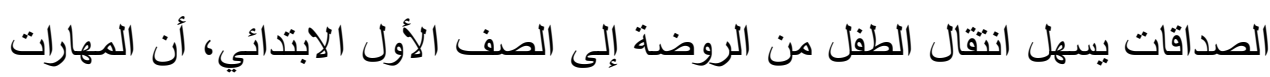

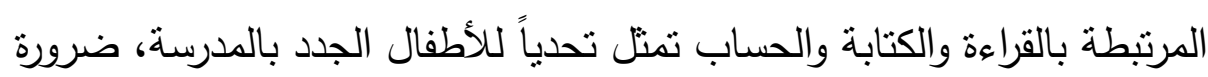
الاستفادة من آراء الأطفال في عملية الانتقال عند تطوير برامج الطفولة. كما أكد (Fabian \& Dunlop,2002) أن الأطفال الذين يبدأون المدرسة

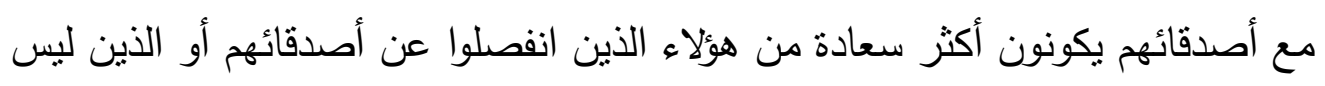


لايهم صداقات قوية، فالصداقات تمكن الأطفال من التعرف على المدرسة من خلال سؤال زملائهم الأكبر منهم سنًا عن المدرسة ونظامها.

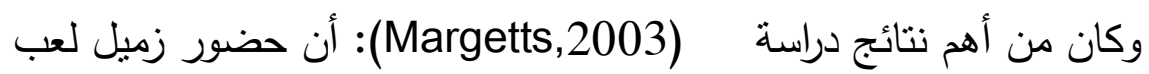
مألوف للطفل في نفس الفصل يعد عامل ذات أهمية كبيرة في تكيف الطفل مع دمع دران المدرسة الابتدائية.

ومن ثم تلعب الصداقات بين الأطفال دورا بارزا عند انتقال الأطفال من الروضة إلى المدرسة الابتدائية حيث تقلل من مشاعر الخوف والقلق عند الطفل وتساعده على التكيف مع البيئة الجديدة. مشكلة الاراسة وتساؤلاتها:

يمثل انتقال الطفل من مرحلة الطفولة المبكرة إلى مرحلة الالتحاق بالمدرسة الابتدائية حدثاً انتقالياً ضخماً في حياته؛ حيث يواجه العديد من التغيرات التي قد تؤثر بالسلب أو الإيجاب على شخصيته المستقبلية، ومن هذه التغيرات: التغير في المناهج وأساليب التذريس، تغيير طريقة تعامل المعلم مع التلميذ، اختلاف المكان والبيئة التعليمية، اختلاف قيم وثقافة كل من الروضة والمدرسة، كذلك اختلاف الأدوار الاجنماعية للتلميذ داخل المدرسة؛ مما يؤدي إلى حالة من القلق الذي ربما يظل تأثنيره على سلوك الطفل لعدة سنوات لاحقة. (46-Fabian \& Dunlop,2007,44) حيث أكدت العديد من الدراسات وجود صعوبة في انتقال الأطفال من لن الروضة إلى المدرسة لأسباب عديدة منها وجود انفصال بين فلسفة رياض الأطفال وفلسفة التعليم الابتدائي وهذا ما أكدت علية دراسة ولئه (Grieble \& Niesesl,2001) وما أنثارت إلبه دراسة (Office for Standards In Education, 2004) من الضرورة أن تكون الموضوعات التي يتتاولها المنهج في الصف الأول الابتدائي مستمدة من الموضوعات التي درسها الطفل في الروضة، كما أكدت دراسة (Margetts,2008) 


$$
\begin{aligned}
& \text { الروضة إلى الصف الأول الابتدائي منها: تكوين الصداقات - والتعرف على } \\
& \text { المعلمين الجدد والقواعد المدرسية والإجراءات المتبعة في الفصول . }
\end{aligned}
$$

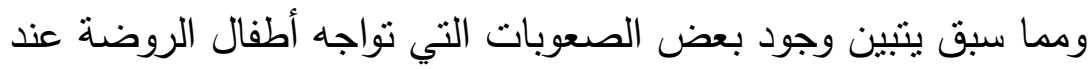

انتقالهم إلى المدرسة الابتدائية لذا فهناك حاجة إلى تحديد هذه الصعوبات ودراسة أسبابها، ومن ثم وضع برنامج مقترح يساهم في تحقيق سلاسة انتقال الأطفال من

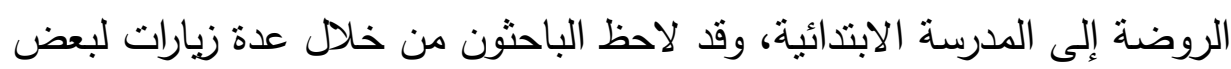

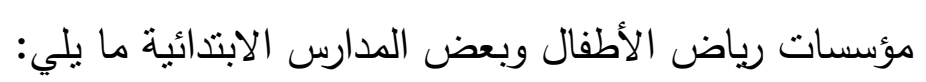

• تعتمد طريقة التدريس في المدرسة الابتدائية على التلقين من قبل المعلم

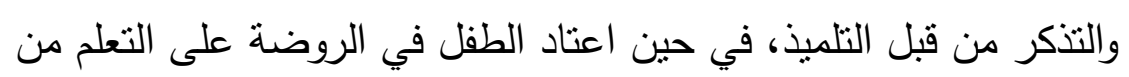

$$
\text { خلال اللعب. }
$$

يختلف شكل وتتظيم الفصل تمامًا من الروضة عن المدرسة الابتدائية؛ حيث

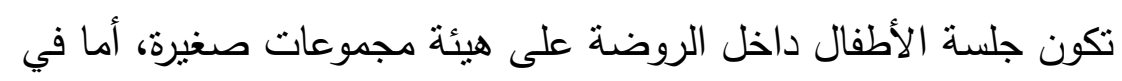
الصف الأول الابتدائي فيجلسون في صفوف وراء بعضها البعض. • تتم عملية التعلم بالروضة من خلال الأركان التعليمية، أما في المدرسة الابتدائية فهي تعتمد على بعض الوسائل البسيطة المعلقة على الحائط مع بع استخدام السبورة والكتب المدرسية.

ونتبلور مشكلة الدراسة في الأسئلة التالية: ا. ما العوامل المؤثرة في عملية الانتقال من الروضة إلى المدرسة الابتدائية r. ما واقع تطبيق ممارسات انتقال الأطفال من الروضة إلى المدرسة

$$
\text { الابتدائية ؟ }
$$

r. ما أهم الخبرات العالمية في الانتقال السلس للأطفال من الروضة إلى

$$
\text { المدرسة الابتدائية ؟ }
$$

ع. ما الروئة المقترحة لتحقيق الانتقال السلس للأطفال من رياض الأطفال 


$$
\begin{aligned}
& \text { إلى المدرسة الابتدائية ؟ } \\
& \text { أهداف الاراسة : - أع } \\
& \text { يمكن تحديد أهداف هذه الدراسة في أنها تسعى إلى : }
\end{aligned}
$$

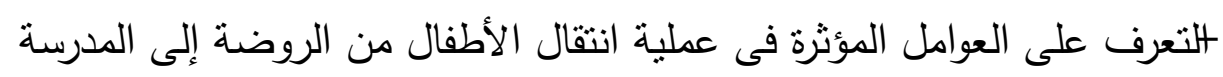
الابتدائية .

تحديد واقع تطبيق ممارسات عملية الانتقال مع توضيح أهم الخبرات العالمية.

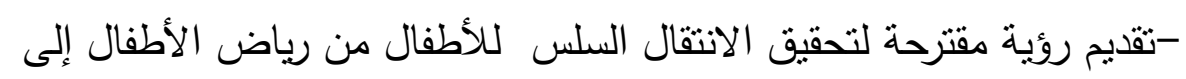

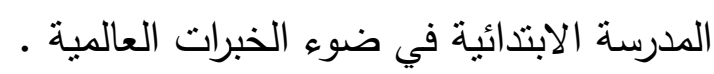

مصطلحات الدراسة :

1- 1 - 1انتقال السلس:

تعرف معظم القواميس الانتقال بأنه" المرور من حالة أو مرحلة أو نمط أو مكان إلى آخر"، ويشير ذلك ضمنيًا إلى فكرة مغادرة أو ترك مرحلة سابقة، حيث ينمو

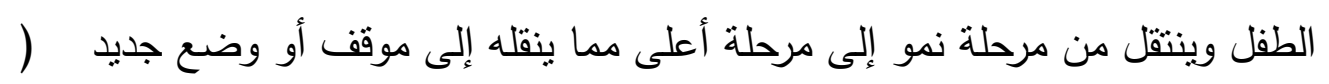
(Myers, 1999,12 وتعرف سلاسة الانتقال بأنها سلسلة من التفاعلات والأنشطة التي تساهم في تكيف الطفل مع المدرسة والتي يتت تتظيمها والتخطيط والتحضير لها قبل الالتحاق بالمدرسة وتحتاج إلى تدريب للأطفال عليها في مراحل الانتقال الأولى قبل أول زيارة له له Sanders,et ) بالمدرسة وتحتاج إلى توجيه وتتجيع من قبل المعلمين والآباء. $($ al, 2005,14

ويعرف البحث الحالي الانتقال السلس بأنه عملية تسلسل وتدرج الخبرات

والأفكار والمعارف وأساليب تدريسها ومعالجتها وشكل وتتظيم الأماكن التي يتم فيها

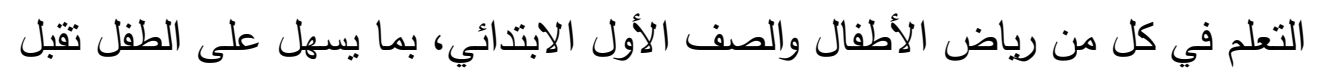
المدرسة الابتدائية.

رياض الأطفال ( Kindergarten ) :- 
رياض الأطفال هي " مؤسسة تربوية خصصت لتربية الأطفال الذين

تتراوح أعمارهم ما بين( 3 : 6 6نوات وتقدم أنشطة وخبرات تربوية تهدف إلى رعاية النمو المتكامل للطفل " .

وهى مؤسسة تربوية للأطفال ما قبل المدرسة وتهدف إلى مساعدتهم على تحقيق التتمية الثاملة في المجالات العقلية والبدنية والحركية والوجدانية والاجتماعية والخلقية والدينية.

\section{المنهج وإجراءات الاراسة :}

استخدمت الدراسة المنهج الوصفي لوصف الظاهرة موضوع البحث في الإطار النظري، واستخدمت الدراسة استبانتين للكثف عن واقع تطبيق معلمات الروضة

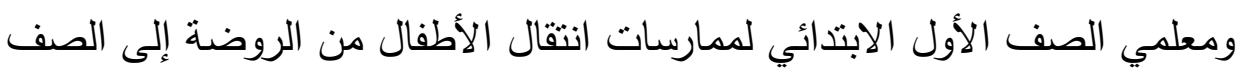
الأول الابتدائي، تم تطبيق استبانة على عينة من معلمات الروضات (50) معلمة في (5) روضات للكثف عن ممارسات الانتقال بالروضة، واستبانة أخرى تم تطبيقها على الى عينة من معلمي الصف الأول الابتدائي (80) معلمًا ومعلمة في (5) مدارس بمحافظة جدة للكثف عن ممارسات الانتقال بالمدرسة الابتدائية؛ ويرجع اختيار العينة إلى تشابه البرامج المقدمة للأطفال بمحافظة جدة مع البرامج التى تقدم للأطفال بالمحافظات

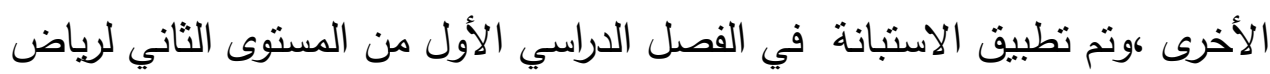
الأطفال K.G.2، في العام الدراسي 2014-2015. أدوات الدراسة: - n

استخدمت الدراسة استبانتين للكثف عن واقع تطبيق معلمات الروضة ومعلمي الصف الأول الابتدائي لممارسات انتقال الأطفال من الروضة إلى الصف الأول الابتدائي: - 20 - n

1- استبانة واقع تطبيق معلمات الروضة لممارسات انتقال الأطقال من رياض الأطفال إلى الصف الأول الابتدائي: 
تكونت الاستبانة من( 21 ) عبارة في صورتها النهائية بعد عرضها على

مجموعة من المحكمين من كليات التربية وكليات رياض الأطفال، وأمام كل عبارة يوجد بهدي

ثلات اختيارات (تطبق - إلى حد ما - لا تطبق)هنم تطبيقها على عينة من معلمات الروضات(50) معلمة في (5) روضات بمحافظة جدة للكثف عن ممارسات الانتقال بالروضة.

تقنين الاستبانة:لقياس مدى ثبات الاستبانة تم استخدام طريقة ألفا لكرونباخ

لتقدير ثنات الاستبانة، وصل معامل الثبات لاستبانة معلمات الروضة إلى هوهذه القيمة تدل على صلاحية الاستبانة للتطبيق وللغرض الذي وضعت من أجله . 2- استبانة واقع تطبيق معلمي الصف الأول الابتدائي لممارسات انتقال الأطفال من رياض الأطفال إلى الصف الأول الابتدائي : الأئي

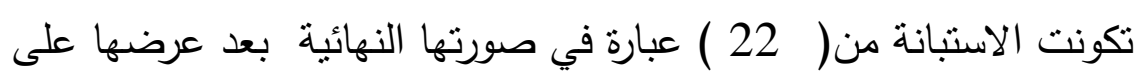

مجموعة من المحكمين من كليات التربية وكليات رياض الأطفال، وأمام كل عبارة

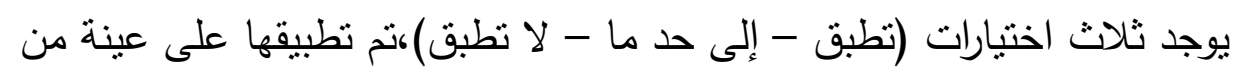
معلمي الصف الأول الابندائي ( 80) معلمًا ومعلمو في ( 5) مدارس بمحافظة جدة للكثف عن ممارسات الانتقال بالمدرسة الابتدائية.

تقنين الاستبانة : لاختبار مدى صدق الاستبانة تم عرضها على ( 12)

محكماً للتأكد من مدى مناسبة عباراتها للغرض الذي وضعت من أجله، وتم تعديل

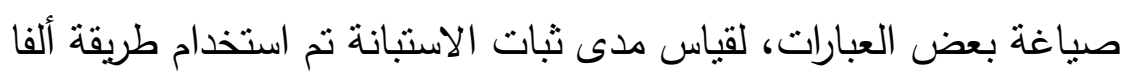
لكرونباخ لتقدير ثبات الاستبانة، وصل معامل الثبات لاستبانة استبانة معلمي الصف الأول الابتدائي إلى 0,77 ،وهذه القيمة تدل على صلاحية الاستبانة للتطبيق وللغرض الذي وضعت من أجله، وتم حساب الصدق الذاتي من المعادلة:

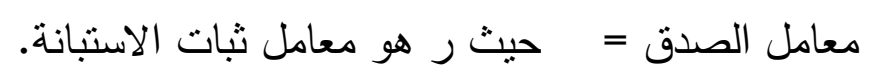
ومن ثم فإن معامل الصدق الذاتي = ل صدق الاستبانة. 


\section{الأساليب الإحصائية : الإيب}

من أجل الإجابة عن أسئلة الدراسة استعملت المعالجات الإحصائية التالية

وذللك باستخدام البرنامج الإحصائي للعلوم الإنسانية (SPSS): المنوسطات الحسابية

ونسبة متوسط شدة الاستجابة من خلال معادلة الوزن النسبي لتحديد درجة تطبيق

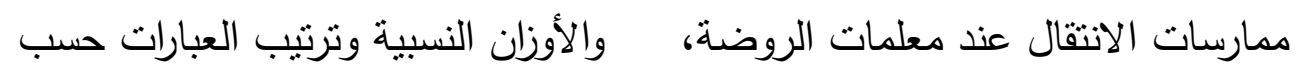
أوزانها النسبية . معارسات

وللاجابة عن السؤال الثاني : ما واقع تطبيق ممارسات انتقال الأطفال من الروضة إلى

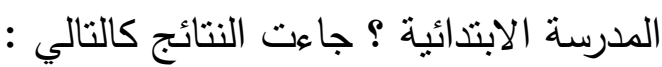
نتائج الدراسة ومناقشتهها :

1 -استبانة واقع تطبيق معلمات الروضة لممارسات انتقال الأطفال من رياض الأطفال إلى الصف الأول الابتدائي: يوضح الجدول التالي الأوزان النسبية

$$
\text { للعبارات وترتيب كل منها: }
$$

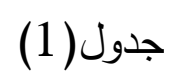

درجة تطبيق معلمات الروضة لممارسات الانتقال

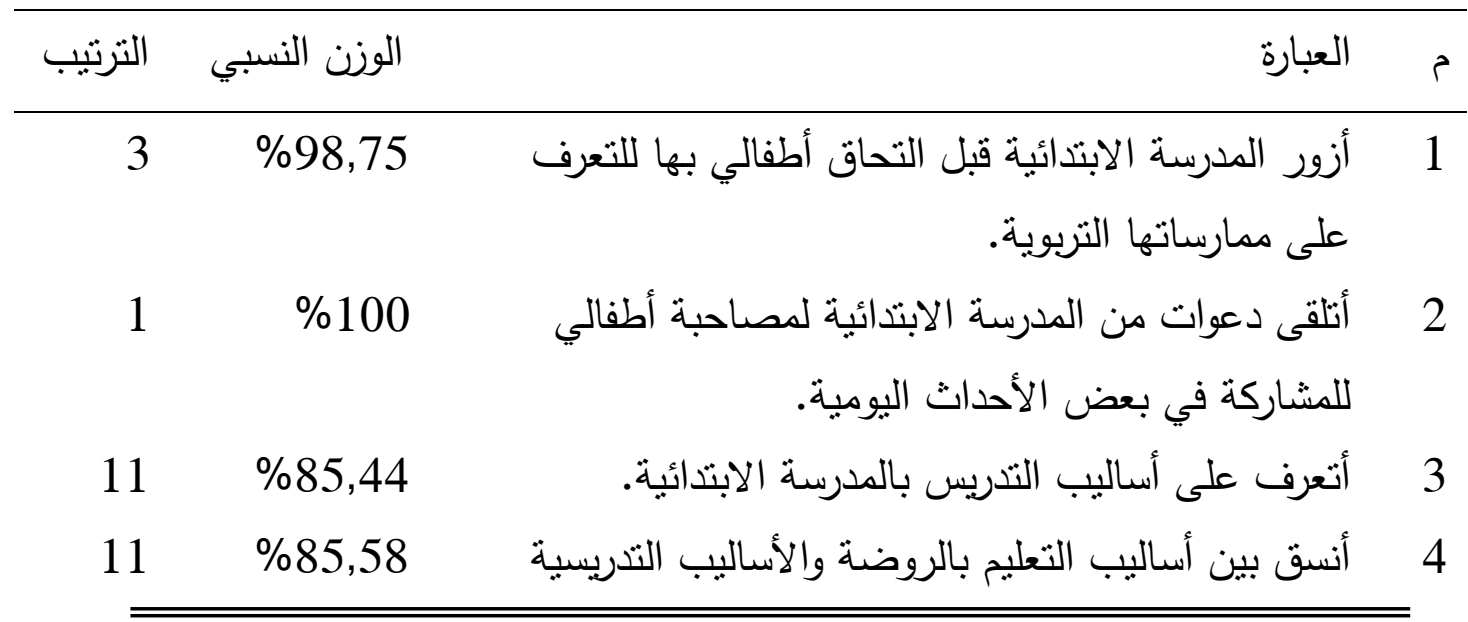


بالمدرسة الابتدائية.

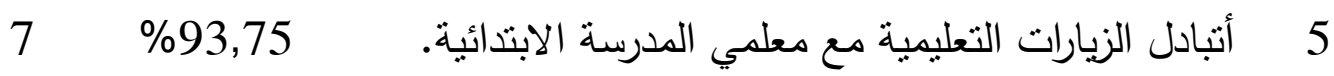

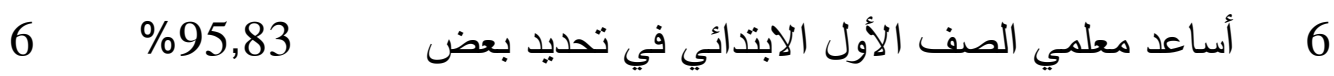

الصعوبات التي تواجه الطفل.

9 \% 89,58

لمناقنة قدرات وخصائص الطفل (الاحتياجات الفردية

لكل طفل).

8 8 812 أجري اتصالات غير رسمية مع معلمي الصف الأول

الابتدائي لتوطيد الصلة فيما بيننا.

أعقد مقابلات مع معلمي الصف الأول الابتدائي لمناقتة

مدى استمرارية تعلم الأطفال.

1

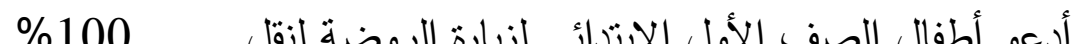

10 خبراتهم للأطفال بالروضة.

$1 \% 100$

11 أعد سجلات مكتوبة عن الخبرات الفردية للأطفال

بالروضه، أبه

10

$\% 89$

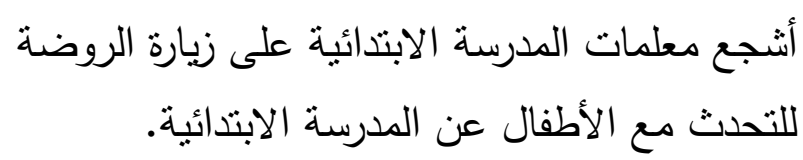

1

$\% 100$

أقدم المشورة الفنية لمعلمي المدرسة الابتدائية في التدريس الابه

$$
\text { لتلاميذ الصف الأول الابتدائي. }
$$

$6 \quad \% 95,83$

14 أقابل الوالدين في حضور معلمي الصف الأول الابتدائي.

$1 \% 100$

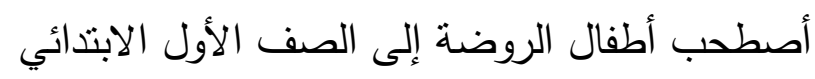

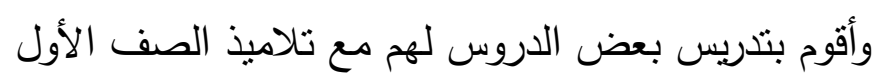

$$
\text { الابتدائي. }
$$

16 أشارك لقاء جماعي أدعوا فيه الآباء والأمهات قبل التحاق 
أطفالهم بالمدرسة.

5 أوجه رسالة إلي أسرة الطفل بها بعض التوجيهات قبل بدء الدراسة.

1379,5

18 أقوم بتيسير التواصل بين الطفل وأسرته.

14

$\% 51$ أنظم بوم مفتوح للآباء والأمهات والأطفال قبل التحاق لئن الطفل بالمدرسة.

$2 \% 98,92$ 20 أزور الأطفال في منازلهم بعد التحاقهم بالمدرسة.

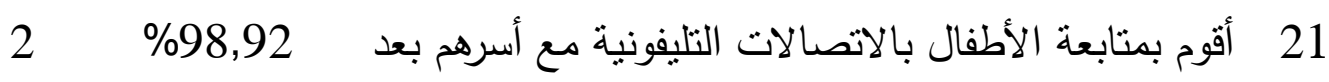
التحاقهم بالمدرسة.

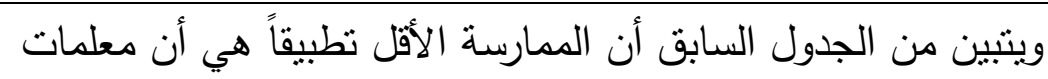

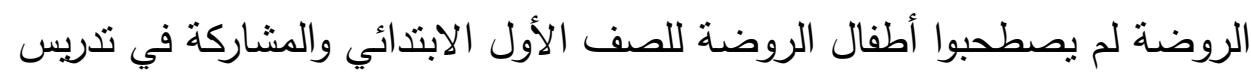

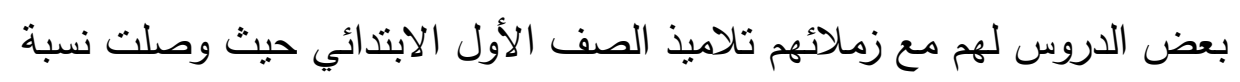
عدم التطبيق إلى 100\% كذلك الممارسة التي تشير إلى أن معلمات الروضة يقمن بعمل زيارات للأطفال في منازلهم بعد التحاقهم بالمدرسة، وممارسة إعداد المعلمات لسجلات مكتوبة عن الخبرات الفردية للأطفال وإرسالها للمدرسة الابتدائية، أيضاً عدم تلقي دعوات من المدرسة الابتدائية لمصاحبة أطفال الروضة للمشاركة في وليه الأحداث اليومية.

أما ثاني الممارسات الأقل شيوعاً وتطبيقاً هي أن معلمات الروضة لا يقمن

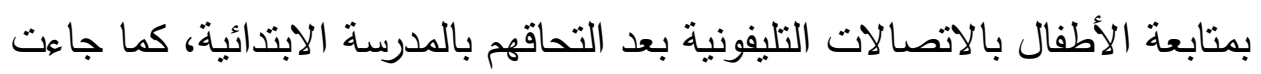

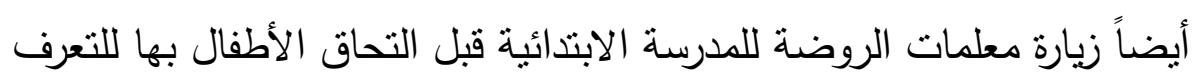
على ممارساتها التربوية في المرتبة الثانية حيث بلغت نسبة عدم التطبيق التبه لئه .\%98,75

ثم توالت الممارسات الأقل تطبيقاً والتي تثير إلى ضعف الاستمرارية والتواصل بين ما تقدمه المدرسة الابتدائية وما تقدمه الروضة وهذا بظهر في عدم تعرف معلمات الروضة على أساليب التدريس التي يتبعها معلمي المدرسة الابتدائية حيث يعتقدون أنها 
تقتصر على الأساليب التقليدية التي تعلموا بها في الماضي، كذلك عدم التنسيق بين

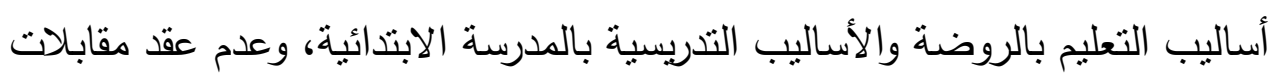

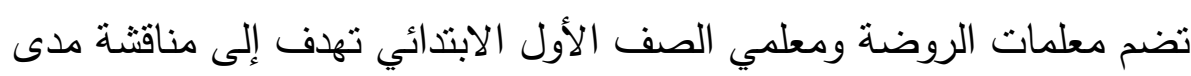
استمرارية تعلم الأطفال.

كما أثنارت بعض الاطعال الممارسات إلى ضعف التواصل بين معلمات الروضة ومعلمي الصف الأول الابتائي وهذا يظهر في أن تبادل الزيارات فيما بينهم محدود باستثناء بعض الاتصالات قليل العدد غير الرسمية فيما بينهم.

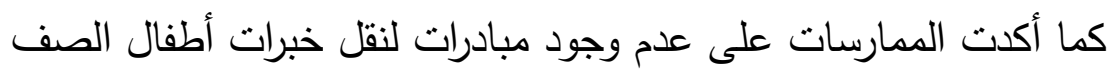
الأول الابتدائي إلى أطفال الروضة بالتحدث معهم.

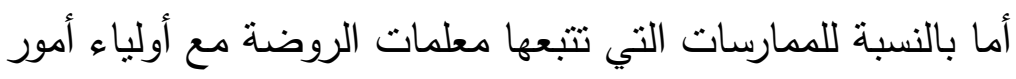

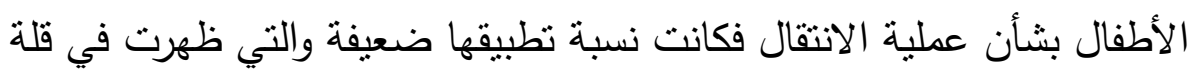

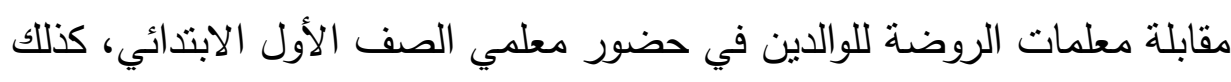

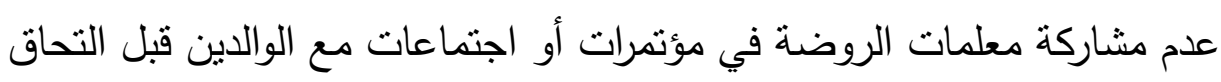
أطفالهم بالمدرسة.

وبالرغم من أن معظم الممارسات لا تطبق إلا أن بعض معلمات الروضة أثنرن بأنهن يقومن بعمل يوم مفتوح للآباء والأمهات والأطفال في نهاية الروضة إنة

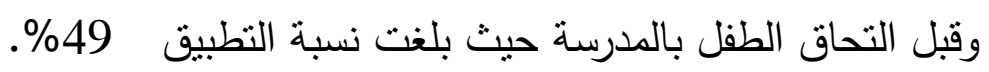

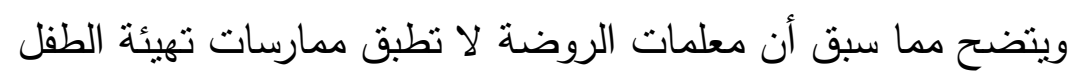
للمدرسة الابتدائية سواء من خلال زيارات المدرسة أو التواصل مع معلمي المدرسة المانة

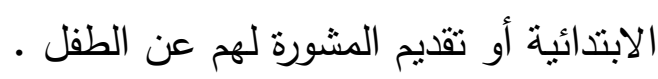

r - استبانة واقع تطبيق معلمي الصف الأول الابتدائي لممارسات انتقال الأطفال من رياض الأطفال إلى الصف الأول الابتدائي: يوضح الجدول التالي الأوزان النسبية للعبارات وترتيب كل منها : جدول (2 ) درجة تطبيق معلمي الصف الأول الابتائي لممارسات الانتقال 
روئة مقترحة لتحقيق الانتقال السلس للأطفال من رياض الأطفال إلى المدرسة الابتدائية في ضوء الخبرات العالمية .

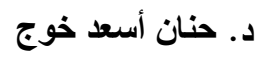

الوزن الترتيب

$$
\text { العبارة }
$$

النسبي

$1 \% 100$

1 أزور الروضة قبل التحاق أطفالها بالصف الأول الابتدائي.

$3 \% 98,2$

2 الابتدائي لحضور يوم بالروضة لتبادل الحديث مع الأطفال

وبعضهم حول المدرسة الابتدائية.

$6 \% 92$

3

$8 \% 90$

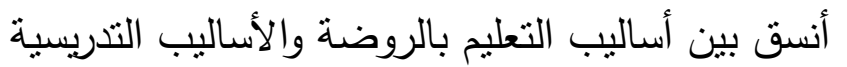

4

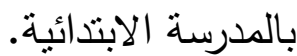

$6 \% 92$

5

$5 \% 96$

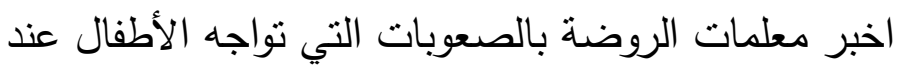

التحاقهم بالصف الأول الابتدائي.

$7 \quad \% 91$

أحضر اجتماعات مع معلمات الروضة لمناقثة قدرات الاتبات التهات

وخصائص الطفل (الاحتياجات الفردية لكل طفل).

$11 \% 76$ 8 الصلة فيما بيننا.

أقابل معلمات الروضة لمناقثة مدى استمرارية تعلم الأطفال. 87\%

$4 \% 97$

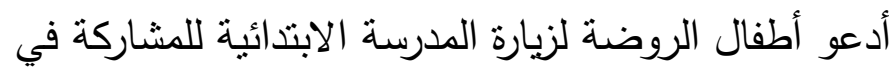
بعض الأحداث البومية.

$2 \% 99$

11 أتلقى سجلات مكتوبة من الروضة عن الاحات الخبرات الفردية

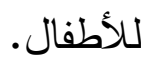

12 أنثجع معلمات المدرسة الابتدائية على زيارة الروضة للتحدث مع الأطفال عن المدرسة الابتدائية

$4 \quad \% 97$

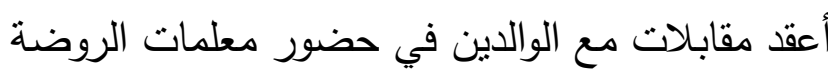
بخصوص الأطفال الجدد.

14 أقوم بتدريس بعض الحصص لأطفال الروضة مع تلاميذ 


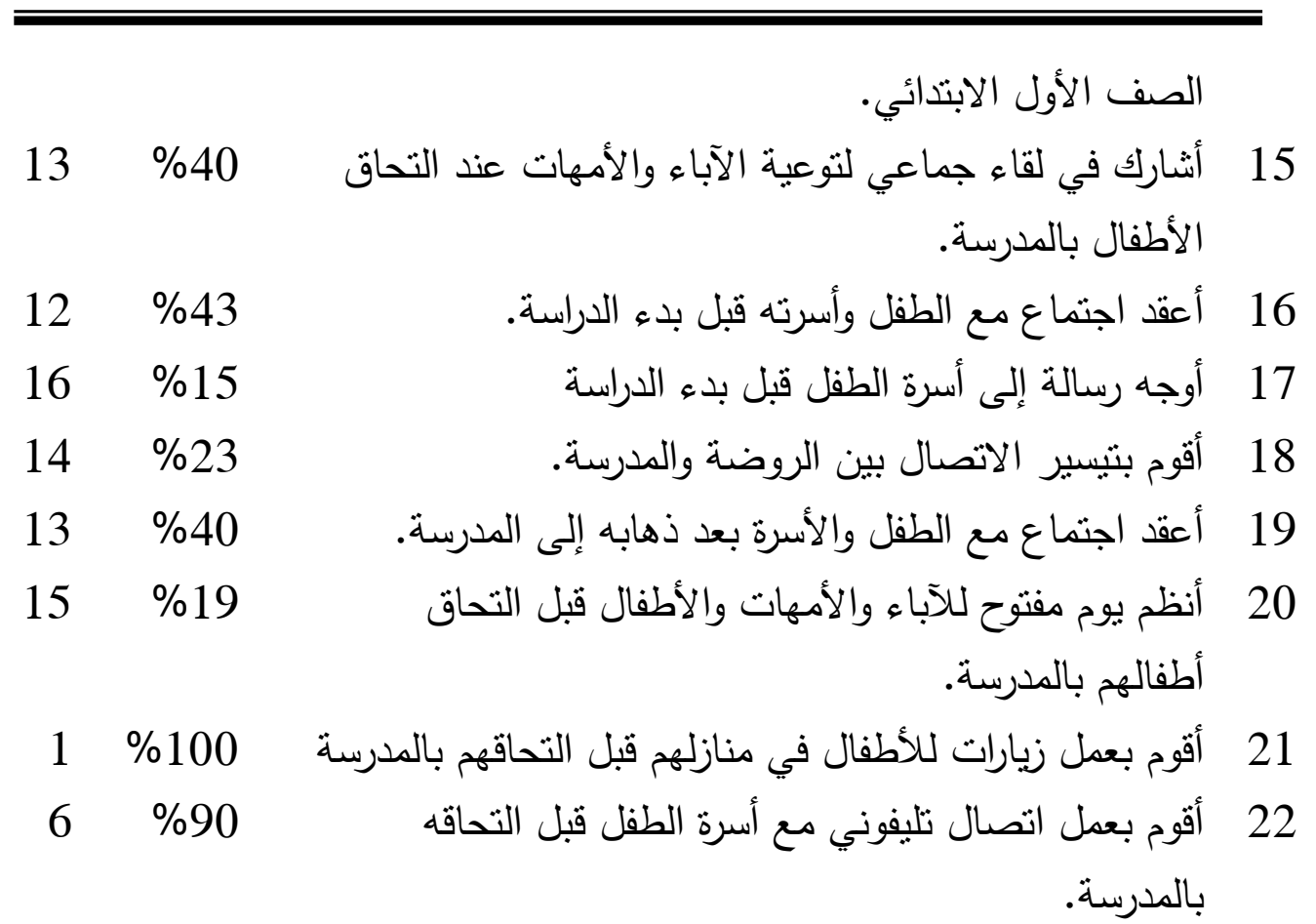

يظهر من الجدول السابق أن معلمي المدرسة الابتدائية لا يقومون بزيارة للروضة

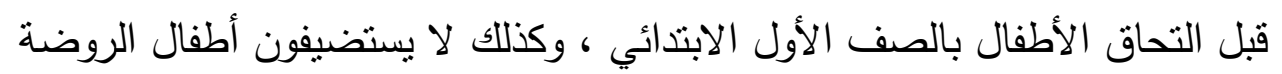

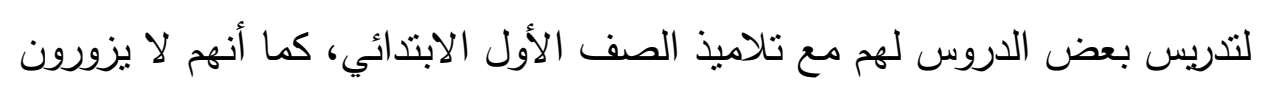

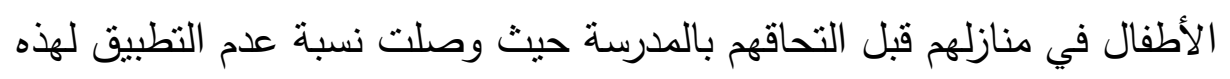

$$
\text { الممارسات إلى 100\%. }
$$

أما ثاني الممارسات الأفل تطبيقا هي التي نتير إلى أن معلمي المدرسة

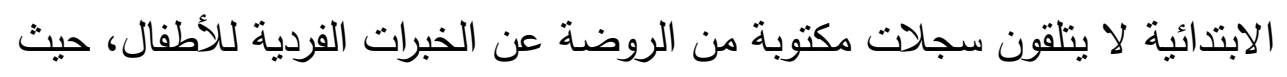

$$
\text { بلغت نسبة عدم تطبيقها إلى 99\% }
$$

كما جاءت الممارسة التي تتير إلى أن معلمي المدرسة الابتدائية لا يتلقون دعوات من الروضة لمصاحبة أطفال الصف الأول الابتدائي لحضور يوم بالروضة الئي

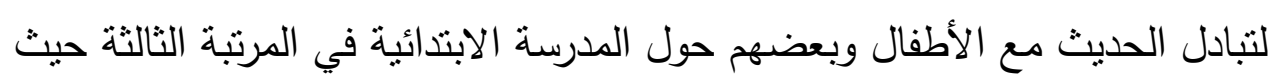
وصلت نسبة عدم تطبيقها إلي 98,2\%. 
ثم توالت الممارسات الأقل تطبيقاً والتي أثنارت في مجملها إلى عدم وجود زيارات سواء من المدرسة الابتدائية إلى الروضة لتبادل الحديث مع الأطفال وبعضهم حول المدرسة الابتدائية، أو زيارات من الروضة إلى إلى المدرسة الابتدائية للمشاركة في بعض الأحداث البومية بها.

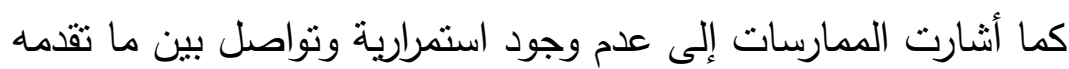
الروضة وما تقدمه المدرسة الابتدائية، وهذا يظهر في عدم التتسيق بين أساليب التعلم بالروضة والأساليب التدريسية بالمدرسة الابتدائية، بالرغم من أن دراسة النة

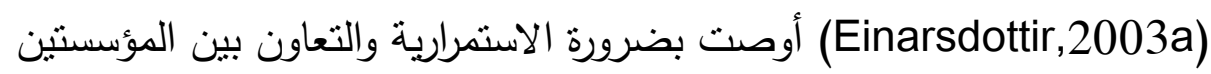
(الروضة - المدرسة الابتدائية) في تتسيق المناهج وطرق التذريس عند انتقال الأطفال من الروضة إلى الصف الأول الابتدائي، كما أن هناك ممارسة غير مطبقة بالمدرسة الهن الابتدائية وهي عدم تعرف معلمي المدرسة الابتدائية بالأنشطة التي تقدم بالروضة. كما تبين من الاستبانة أن هناك ضعف في التواصل بين معلمات الروضة ومعلمي المدرسة الابتدائية، ويظهر ذلك في عدم تبادل الزيارات مع بعضهم البعض، كذلك عدم وجود اتصالات سواء رسمية أو غير رسمية مع بعضهم البعض لتوطيد الصلة فيما بينهم ،على الرغم من أن دراسة( Bennett,2000) توصلت إلي نتيجة مؤداها أن عملية الانتقال الفعالة تتعرقل بسبب نقص مهارات التواصل بين معلمات درات التهات الروضة ومعلمي المدرسة الابتدائية. وبالرغم من وجود الكثثر من الممارسات التي لا نطبق عند انتقال الطفل من الروضة إلى الصف الأول الابتدائي إلا أن هناك عدد من الممارسات التي تطبق بشكل ملحوظ كتوجيه رسالة إلى الطفل وأسرته قبل بدء الدراسة في المدرسة الابتدائية والتي تطبق بنسبة 85\%، كذلك عمل يوم مفتوح للآباء والأطفال بعد الالتحاق بالمدرسة وبلغت نسبة التطبيق 79\%، أما مشاركة معلمي المدرسة الابتدائية في

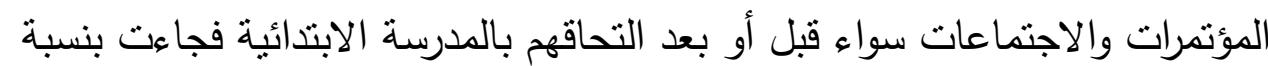
تتراوح بين 58: 60\%. 
أما عن علاقة معلمي المدرسة الابتدائية بالوالدين فقد تبين من بعض عبارات

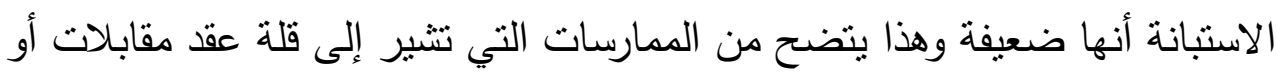

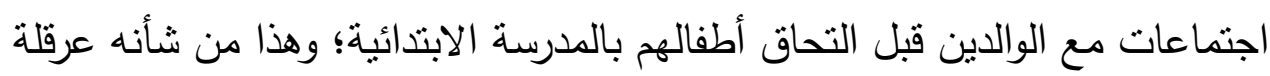

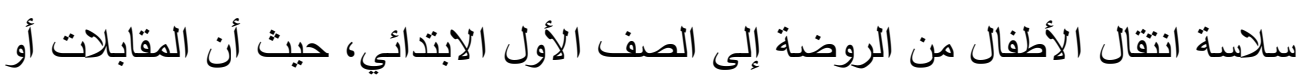
الاجتماعات مع الوالدين قبل التحاق الأطفال بالمدرسة تعد أمرا ضروريا لتعرف الته

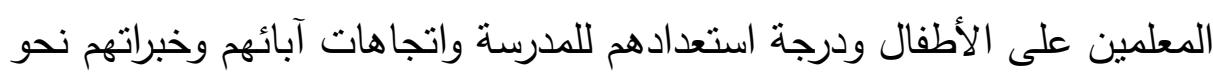

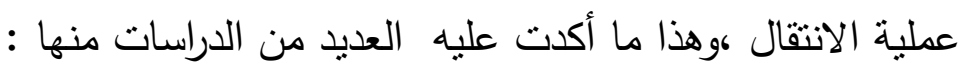
(Fabian \& Dunlop,2005) ،(Grieble\& Niesesl ,1999), (Mcinture, et al ,2007)‘(Rimm \& Pianta, 1999) ‘(Brostrom,2003)(Peter, 2000) ‘(Nelson, 2004).

ومن ثم يمكن استخلاص عدة نتائج من أهمها:

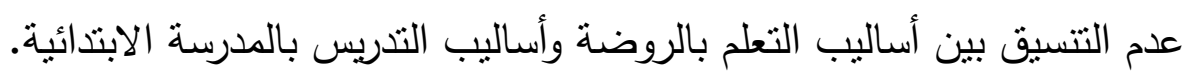

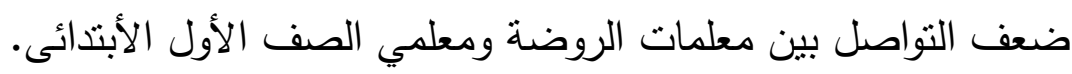
ضعف الاستمرارية والتواصل بين ما يقدم في رياض الأطفال من خبرات وما يقدم من مناهج في المدرسة الأبتدائية. ضعف الاتصال بين كل من معلمات الروضة ومعلمي الصف الأول الابتدائي

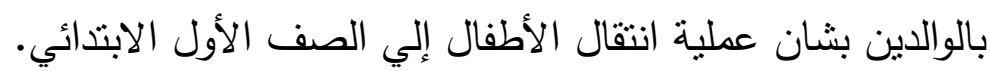

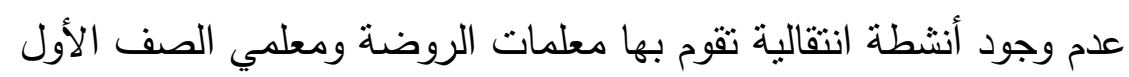
الابتدائي لتهيئة الأطفال للانتقال من الروضة إلي المدردة الإنها الابتدائية. توصيات الاراسة :

يضع البحث رؤية مقترحة لتحقيق الانتقال السلس للأطفال من رياض الأطفال إلى المدرسة الابتدائية، في ضوء النتائج السابقة تتمثل أبعادها في: 
( ) تطوير مناهج الصفوف الأولي من التعليم الأبتدائى لتضم خبرات وأنشطة تعمل علي التتمية المتكاملة للطفل في جميع الجوانب، وتراعى اهتماماته وقدراته

$$
\text { وميوله. }
$$

r ) تطوير مناهج رياض الأطفال لتحقيق استمرارية الخبرات ، بحيث تبنى الخبرات التي يتلقاها الطفل بالمدرسة علي الخبرات السابقة التي اكتسبها من

$$
\text { الروضة. }
$$

ץ) إعادة تتظيم الفصل في المدرسة الابتدائية ليضم مجموعة من الأركان

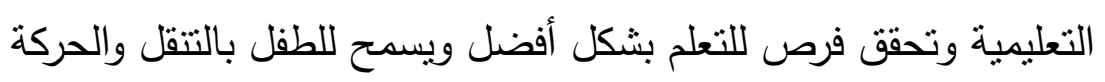

$$
\text { والتحدث مع زملائه. }
$$

§) إعداد دورات تدريبية لمعلمات الروضة ومعلمي الصف الأول الابتدائي لزيادة فرص الاتصال وتبادل الخبرات فيما بينهم لدعم عملية انتقال الأطفال

$$
\text { من الروضة إلي المدرسة الابتدائية. }
$$

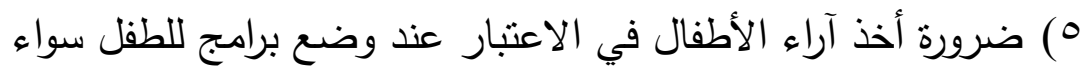

$$
\text { بالروضة أو بالمدرسة الابتدائية. }
$$

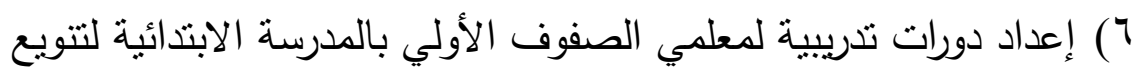
طرق التدريس التي يستخدمونها مع التلاميذ.

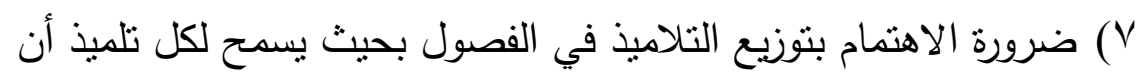
يكون معه مجموعة من أصدقائه من الروضة.

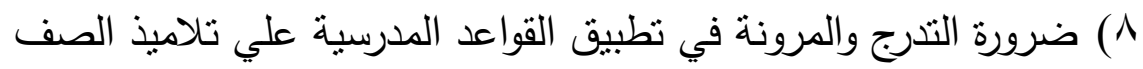

$$
\text { الأول من التعليم الابتدائي. }
$$

9) زيادة فرص التواصل بين المدرسة والمنزل من خلال دعوة الآباء لحضور يوم مفتوح قبل التحاق أطفالهم بالمدرسة لتقديم معلومات عن طفلهم ومشاركتهم في برامج تهيئة الطفل للمدرسة. 
• ( ) القيام بسلسلة من زيارات الأطفال للمدارس الابتدائية والفصول الدراسية وتشمل هذه الزيارات: القيام بجولة للمبنى المدرسي والملعب، تتاول الطعام

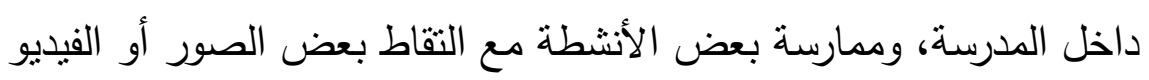
لهذه الأنشطة.

11) السماح للأطفال بالتعبير عن مشاعرهم حول المدرسة الابتدائية من خلال

$$
\text { اللعب الدراسي والقصص. }
$$

r ( ) لتخفيف القلق من قواعد وإجراءات المدرسة يمكن أن تقوم معلمة الروضة بمشاركة الأطفال في ألعاب تساعدهم في التعرف على هذه القواعد

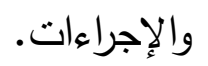

با (1) دعوة معلمي المدرسة الابتدائية لزيارة الروضة والتحدث مع الأطفال عن

$$
\text { المدرسة. }
$$

ع ( ) تكوين علاقات بين المعلم والطفل وبين الطفل وزملائه. 10) توضيح المشاهد والأحداث غير المألوفة من خلال جولة للأطفال داخل ولئ المدرسة.

7 (1) تشجيع التعاون بين الآباء والمعلمين: ضروري في مساعدة الأطفال على

$$
\text { النجاح. }
$$

اهتمام وزارة التربية والتعليم بتقديم برامج تهيئة للطفل، وذللك بتكليف الإدارات (IV

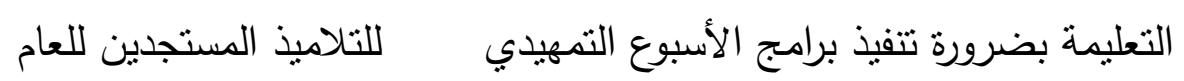

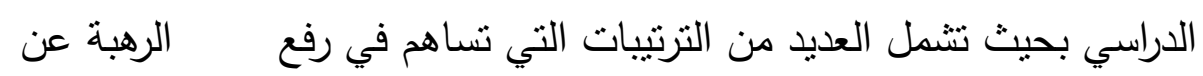

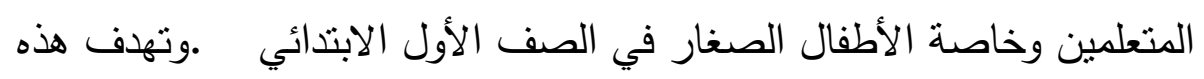

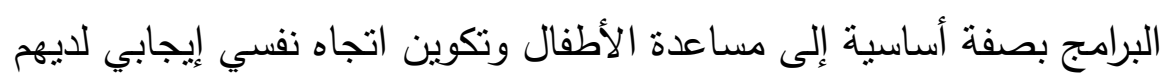

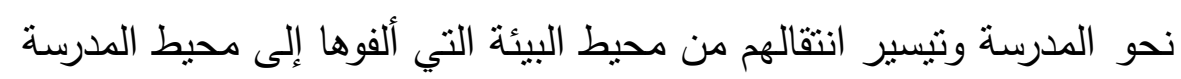
تدريجيًا بما يخفف شعور الخوف والرهبة في نفس الطفل، ويحل محلة شعور الألفة والطمأنينة، كما تهدف هذه البرامج إلى توفير الفرصة للمعلم للتعرف على 
شخصية كل طفل وأنماط سلوكه المختلفة، ومن أمثلة ما يمكن أن يقوم به المعلمون في تهيئة أطفال الصف والماطل سلوكه لأول الابتدائي: تعريف الأطفال بمرافق المدرسة، وتدريبهم على أصول الجلسة الصحيحة ربحيث الصيث تكون المسافة بين وجه الطفل والمقعد الذي يجلس عليه قريبة من 30 سم. tلتدريب على طريقة إمساك القلم وفتح الكتاب وتقليب صفحاته برؤوس الأصابع دون استخدام اللعاب.

تثريبهم على استعمال الممحاة لكي لا يمزق أحدهم الصفحة وهو يمحو ما

$$
\begin{aligned}
& \text { عليها. } \\
& \text { مراجع الدراسة : } \\
& \text { أولاً / المراجع العربية : العراسه : }
\end{aligned}
$$

( (1)الخليلي، أمل عبد السلام (2005). إدارة الصف المدرسي. عمان: دار صفاء للنشر

$$
\text { والتوزبع. }
$$

(Y)بيرد، بولي (2007). كيف تساعد طقلك على التعليم في المرحلة الابتدائية؟ . ترجمة خالد العامري، القاهرة: دار الفاروق للنشر والتوزيع.

(r)بدر، سهام محمد (2002).اتجاهات الفكر التربوي في مجال الطقولة ـ ـالقاهرة: مكتبة الأنجلو المصرية. (ع)بدير ،كريمان عبد السلام ( 2004).الرعاية المتكاملة للأطفال الأنشطة الحركية - الأنشطة المعرفية - الأنشطة الفنية. القاهرة: عالم الكتب. (0)حافظ بطرس،بطرس (2014) .تنمية المفاهيم والمهارات العلمية لأطفال ما قبل علمه

$$
\text { المدرسة، ط7، دار المسيرة . }
$$

(T) الجرواني، هالة و المشرفي، إنشراح ( 2010) • إعداد الطقل لمرحلة الروضة ، الدار المصرية اللبنانية.

(V) الثيخ ،محمود يوسف (2007).مشكلات تريوية معاصرة : مفهومها - مظاهرها - أسبابها - علاجها. القاهرة: دار الفكر العربي. 
روئة مقترحة لتحقيق الانتقال السلس للأطفال من رياض الأطفال إلى المدرسة الابتائية في ضوء الخبرات العالمية .

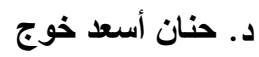

(^) الناشف ، هدى محمود ( 2006) ـ قضايا معاصرة في تربية الطفولة المبكرة

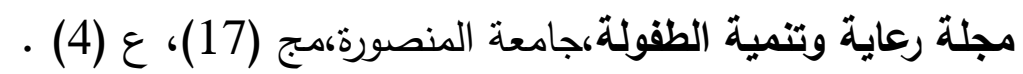

(9) إعلان دمثق لرعاية وتربية الطفولة|المبكرة ( 2010) ـ المؤتمر العربيالإقليمي

حول رعاية وتربية الطفولة المبكرة "السياسات والبرامج" ،انترنت متاح على الرابط

http://www.esyria.sy/index.php?p=syrianews\&filename $=20100$ 9230900012

$$
\text { ت تاريخ الدخول 2015/6/2 }
$$

سبتي ، عباس ( 2010 ) ـ دراسة الحاسوب كوسيلة تعليم وتعلم برياض

الأطفال بدولة الكويت- دراسة مكتبية، 2010. انترنت مناح على الرابط

http://kenanaonline.com/users/azazystudy/posts/404929

$$
\begin{aligned}
& \text { تاريخ الدخول 2013\03\24. } \\
& \text { ثانياً / المراجع الأجنبية : }
\end{aligned}
$$

(1) Bennett, S.N. (2000).Progression and Continuity in Pre School and Reception Classes. Full Report, online, Available: http://www.regard.ac.uk/research_findings/R000222791/report/pdf1 3December.

(2) Brostrom, S. (2003). Probiems and Bariers in Children's Learning When They Transit from Kindergarten to Kindergarten Class in School, European Early Childhood Education Research Monograph, Series no.1.

(3) Einarsdottir, Johanna (2003a). Towards a smooth transition from preschool to primary school in Iceland. paper presented at the British educational research association annual conference، Horiot - watt university، Edinburgh، 11 - 13 September. 
(4) Einarsdottir, Johanna (2003b).When the Bell Rings we have to go Inside: Preschool Children's Views on the Primary School. European Early Childhood Education Research Journal: Transitions, Series, No. (1), 35-50.

(5) Fabian, Hilary (1998). Induction to School and Transitions through Key Stage one. Practice and Perceptions, Unpublished $\mathrm{PhD}$, thesis, University of Coventry.

(6) Fabian, Hilary (2000a).Small Steps to Starting School. International Journal of Early Years Education، 8 (2), 141153.

(7) Fabian, Hilary (2000b).A seamless Transition.Paper Presented on the $10^{\text {th }}$ European Conference on Quality in Early Childhood Education, London University, $29^{\text {th }}$ of August.

(8) Fabian, Hilary \& Dunlop, Alice (2002).Empowering Children for Transitions. (eds.)، Transitions in the Early Years: Debating Continuity and Progression for Children in Early Education, London, Rout ledge Falmer.

(9) Fabian, Hilary \& Dunlop, Alice (2005). Transitions in the Early Years. London, Rout ledge falmer.

(10)Fabian,Hilary \& Dunlop,Alice (2007). Outcomes of Good Practice in Transition Processes for Children Entering Primary School. Working Papers in Early Childhood Development, N.(42), Bernard Van Leer Foundation, UNISCO, May.

(11) Graham, C. \& Hill , M. (2003).Negotiating the Transition to Secondary School.(SCRE Spotlight 89), Glasgow, University of Glasgow, SCRE Centre. 
روئية مقترحة لتحقيق الانتقال السلس للأطفال من رياض الأطفال إلى المدرسة الابتائية في ضوء الخبرات العالمية .

(12)Grieble, W. \& Niesesl , R. (1999).From Kindergarten to School : A Transition for the Family. Paper EECERA 9th European Conference on Quality in Early Childhood Education, Helsinki, 1-4 September.

(13)Grieble ،W. \& Niesesl (2000). The Children Voice in the Complex Transition into Kindergarten and School. Paper Presented at 10th European Conference on Quality in Early Childhood Education Complexity, Diversity and Multiple Perspectives in Early Childhood Services, London, 29 August -1 September.

(14)Grieble,W. \& Niesesl ,R. (2001). Transition to School: What Children Tell About School and What They Teach Us. Paper presented at the EECERA 11th European Conference on Quality in Early Childhood Education,Early Childhood Narratives - Early Childhood and New Understanding of the Mind, 29th August - 1st September, Alkmaar,Netherlands.

(15)Grieble,W. \& Niesesl ,R.(2002).Co- Constructing Transition into Kindergarten and School by Children، Parents and Teachers In H. Fabian \& A. Dunlop. (eds.), Transitions in the Early Years: Debating Continuity and Progression for Children in Early Education, London, Rout ledge Falmer.

(16)Jiahui Zhang, Tao Xin: Boosting Early Development: The Mixed Effects of Kindergarten Enrollment Age, US - China Education Review. ISSN 1548-6613, 2012,

(17)Margetts,Kay (2000a). Children's Adjustment to the to the First Year of Schooling: Indicators of Hyperacivity, Internalizing and Externalizing Behaviours. Paper Presented at the Australian 
روئية مقترحة لتحقيق الانتقال السلس للأطفال من رياض الأطفال إلى المدرسة الابتائية في ضوء الخبرات العالمية .

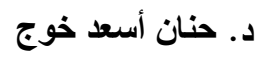

Association for Research in Education Conference Sydney, 4-7 December.

(18)Margetts, Kay (2002a).Child Care Arrangement, Personal, Family and School Influences on Children's Adjustment to the First year of Schooling. The University of Melbourne, May.

(19)Margetts, Kay (2002b) .Starting school matters: Supporting children's transition to school. Proceedings of the. Early Childhood Matters Conference .

(20)_ (2003).Children Bring more to School than Their Backpacks:

Starting School down Under. Journal of Education Early Childhood Education Research Monograph, 1, 5-14.

(21)Margetts, Kay(2006).I Just got my head Muddled up: Children's Perspectives of Starting School. Paper Presented at the EECERA 16th Annual Conference Reykjavik, Iceland, 30 August - 2 September.

(22) Margetts, Kay (2008) - transition to school :what children think about it works and how it is going to be different things .summary of paper presented at the 18th EECERA conference Satvanger , 2-6 September, the university of Melbourne

(23)Mcinture, Laura, et al (2007).Transition to Kindergarten: Family Experiences and Involvement. Early Childhood Education Journal, Vol. (35), No. (1), Aug.

(24)Myers, G.Robert (1999). Linkages between Home، Preschool and Primary School. Coordinators' Notebook No. 21, The Consultative Group on Early Childhood Care and Development, The Consultative Group on ECCD. Washington D.C.: World Bank. 
روئية مقترحة لتحقيق الانتقال السلس للأطفال من رياض الأطفال إلى المدرسة الابتائية في ضوء الخبرات العالمية .

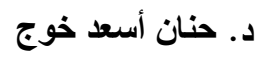

(25)Nelson, Regena Fails (2004).The Transition to Kindergarten. Early Childhood Education Journal, Vol (32), No. (3), December.

(26) Office for Standards In Education (2003).The Education of the Six Years Olds in England، Denmark and Finlan . an International Comparative Study (HMI 1660), London, OFSTED.

(27) Office for Standards In Education (2004). Transition from the Reception Year to Year 1. an Evaluation by $\mathrm{HMI}$ (HMI2221), London, OFSTED.

(28) Peter, Sally (2000).Multiple Perspective on Continuity in Early Learning and The Transition to School. Paper Presented at European Early Childhood Education Research Association Conference, University of London,London, 29 August 1 September.

(29) Phatudi, Nkidi (2007).A study of Transition from Pre School and hom Contexts to Grade 1 in A Developing Country", PHD, Faculty of Education University of Pretoria.

(30) Rimm, Kaufman \& Pianta, R (1999).Patterns of Family School Contact in Pre- School and Kindergarten. School Psychology Review, 28,426-38.

(31) Samuel, Ngatuiya (2006).Pre - School Education and School Readiness: The Kenya Experience, Ade Biennale on Education in Africa, Bibreville, Gabon, March 27-31.

(32) Sanders, Daw, et al (2005). A Study of the Transition from the Foundation Stage to Key Stage (1). National Foundation from Education Research، March. 
روية مقترحة لتحقيق الانتقال السلس للأطفال من رياض الأطفال إلى المدرسة الابتدائية في ضوء الخبرات العالمية .

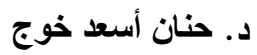

(33) Stephen, C. \& Cope, P. (2001).Moving on to Primary 1, an Exploratory Study of the Experience of Transition from Pre School to Primary . Insight 3, Edinburgh,Scottish Executive. 